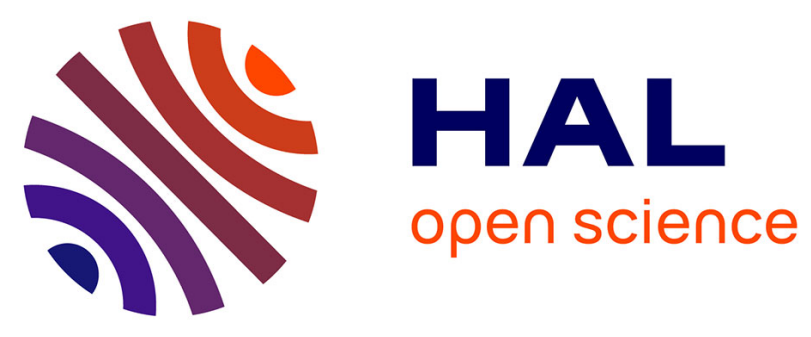

\title{
New hybrid MOF/polymer composites for the photodegradation of organic dyes
}

Chaima Brahmi, Mahmoud Benltifa, Cyril Vaulot, Laure Michelin, Frédéric

Dumur, Franck Millange, Michel Frigoli, Aissam Airoudj, Fabrice

Morlet-Savary, Latifa Bousselmi, et al.

\section{To cite this version:}

Chaima Brahmi, Mahmoud Benltifa, Cyril Vaulot, Laure Michelin, Frédéric Dumur, et al.. New hybrid $\mathrm{MOF}$ / polymer composites for the photodegradation of organic dyes. European Polymer Journal, 2021, 154, pp.110560. 10.1016/j.eurpolymj.2021.110560 . hal-03251026

\section{HAL Id: hal-03251026 \\ https://hal.science/hal-03251026}

Submitted on 5 Jun 2021

HAL is a multi-disciplinary open access archive for the deposit and dissemination of scientific research documents, whether they are published or not. The documents may come from teaching and research institutions in France or abroad, or from public or private research centers.
L'archive ouverte pluridisciplinaire HAL, est destinée au dépôt et à la diffusion de documents scientifiques de niveau recherche, publiés ou non, émanant des établissements d'enseignement et de recherche français ou étrangers, des laboratoires publics ou privés. 


\title{
New hybrid MOF/polymer composites for the photodegradation of organic
}

dyes

Chaima Brahmi a,b,c,d, Mahmoud Benltifa d, *, Cyril Vaulot a,b, Laure Michelin a,b, Frédéric Dumur e, Franck Millange f, Michel Frigoli g, Aissam Airoudj a,b, Fabrice Morlet-Savary a,b, Latifa Bousselmi c, Jacques Lalevée a,b, ${ }^{*}$

a University of Haute-Alsace, Strasbourg University, CNRS, IS2M UMR 7361, F-68100 Mulhouse, France

${ }^{\mathrm{b}}$ Laboratory of Wastewaters and Environment, Center for Water Research and Technologies CERTE, BP 273, Soliman 8020, Tunisia

' University of Carthage, National Institute of Applied Sciences and Technology, Tunis 1080, Tunisia

${ }^{d}$ Aix Marseille Univ, CNRS, ICR, UMR7273, F-13397 Marseille (France)

e University of Versailles St-Quentin-en-Yvelines 78035 Versailles Cedex, France ${ }^{\mathrm{f}}$ PEIE Research Chair for the Development of Industrial Estates and Free Zones, Center for Environmental Studies and Research, Sultan Qaboos University, Al-Khoud 123, Muscat, Oman

*Corresponding author: Jacques.lalevee@uha.fr and mahmoud_fsm@yahoo.fr

\begin{abstract}
Hybrid Metal Organic-Frameworks (MOF)/polymer materials have gathered many researcher's consideration thanks to their varied functionalities and high processability. Herein, Metal Organic Frameworks (MOFs) have been successfully incorporated into an acrylate polymer network by photopolymerization upon mild visible light irradiation at 405 $\mathrm{nm}$. The synthesized MOF/polymer composites were very efficient for Acid Black removal from water reaching $96 \%$ of decomposition after 30 and 45 min of UV-Lamp irradiation in the presence of MIL-53(Cr)/polymer and HKUSTI-1(Cu)/polymer composites, respectively. Probing further, the photo-composites were characterized by several techniques including Thermogravimetric Analysis (TGA), Fourier-Transform Infrared Spectroscopy (FTIR), Scanning Electron Microscopy (SEM), Transmission Electron Microscopy (TEM), Energy-dispersive X-ray
\end{abstract}


analyses (EDX), X- Ray Diffraction analysis (DRX), Brunauer, Emmett and Teller (BET) specific surface area, Atomic Force Microscopy (AFM), Dynamic Mechanical Analysis (DMA) and UVVisible diffuse reflectance spectroscopy. The different methods used to characterized the MOF-containing polymers revealed these polymers to exhibit a high rigidity, an excellent thermal stability, an interesting band gap energy as well as an exceptional stability after their reuse for many photocatalytic treatment cycles.

\section{Introduction}

Water is the most important resource for living species. Protecting scarce water bodies from pollution caused by continuous population growth, urbanization and industrial revolution, is a vital responsibility shared between states and citizens ${ }^{1}$. In fact, during the last few years, water quality was deteriorated because of its contamination by emergent pollutants such as pharmaceutical compounds ${ }^{2}$, personal care products ${ }^{3}$ and especially organic dyes released into the environment by the paper, textile, cosmetic, food and pharmaceutical industries ${ }^{4}$. These synthetic dyes represent a threat for human health and ecosystem because of their toxicity, non-biodegradability, and their carcinogenic effects 5 .

To mitigate the harmful effect of those organic dyes on the environment and to satisfy the demands of people for clean and safe water, several chemical, physical and biological techniques have been employed to remove those pollutants from water including adsorption on activated carbon ${ }^{6}$, chemical precipitation ${ }^{7}$, microbial degradation $^{8}$, electrocoagulation ${ }^{9} .$. However, these methods are generally not economic, difficult to manage, and lead usually to the formation of another type of pollution by producing sideproducts sometimes more toxic than the initial compounds ${ }^{10,11}$. Therefore, these conventional processes can't be considered as durable and sustainable solutions for the treatment of such biorecalcitrant pollutants. In this context, great attention has been focused on advanced oxidation processes based on highly reactive species. Though, photocatalysis has emerged as a new, viable, green and performant technique for the total removal and mineralization of numerous emergent pollutants ${ }^{12-15}$. Photodegradation consists on irradiating a large band gap of semiconductors such as Titanium dioxide which is the most used photocatalyst nowadays, thanks to its low cost, chemical stability and abundance ${ }^{1}$. However, pure $\mathrm{TiO}_{2}$ absorbs only $4 \%$ of sunlight due to its high band gap energy $(3.2 \mathrm{eV})$, and needs generally the presence of oxidative agents 
such as hydrogen peroxide in aqueous solution to achieve the total degradation of organic pollutants ${ }^{1}$. Consequently, it was interesting for researchers to develop new photocatalysts systems like $\mathrm{ZnO}^{16}, \mathrm{WO}_{3}{ }^{17}, \mathrm{CdS}^{18}, \mathrm{ZnS}^{19}$, Polyoxometalates ${ }^{15} \ldots$ Metals Organics Frameworks (MOFs) are a more complex photocatalytically active material that have received a lot of attention from researchers for their adsorption properties thanks to their highly specific surface area. However, their photocatalytic activity has not been too much explored.

Metals Organics Framework (MOFs), known as porous coordination polymers (PCPs), are a new category of crystalline porous materials, formed by a periodic network between metal ions or clusters with organic ligands such as terephtalatic and trimesic acids, linked by strong coordination bonds ${ }^{20}$. Depending on their desired applications and thanks to the unlimited possible combinations between metals and ligands, several type of MOFs with different chemical and physical properties, could be synthesized ${ }^{21}$. Consequently, these materials were applied in various fields such as biomedicine for drugs vectorization ${ }^{22}$, gas storage ${ }^{23}$, uranium extraction $^{24}$ as well as photocatalysis ${ }^{25}$ thanks to the behavior of certain MOFs like semiconductors. In fact, upon irradiation, electrons could transit from the highest occupied molecular orbital (HOMO) to the lowest unoccupied molecular orbital (LUMO) creating holes in $\mathrm{HOMO}^{26}$. The generated holes could oxidize directly the pollutants adsorbed on its surface or generate highly reactive chemicals such as ${ }^{\circ} \mathrm{OH}$ radicals which promote the degradation.

Similarly, the electron ejected to the LUMO can directly reduce the adsorbed pollutant or react with $\mathrm{O}_{2}$, producing superoxide radicals $\left(\mathrm{O}_{2}{ }^{-}{ }^{-}\right)$.

Latterly, researchers have focused their attention on developing MOFs acting like photocatalysts. MOF- $5^{27}$, UiO-66(Zr ${ }^{28}$ and MIL-125(Ti) ${ }^{29}$ were firstly used for the degradation of phenol, organophosphate and methylene blue respectively. Though, the effectiveness of these photosensitive materials were limited to UV light $(\lambda<365 \mathrm{~nm})^{26}$. Hence, MOFs active under visible light were more required for heterogeneous photocatalysis. In this sense, in 2017 Wang and al have reported the Fe-based MOFs performance for several photocatalytic applications including pollutants degradation, $\mathrm{CO}_{2}$ reduction and water oxidation ${ }^{30}$. Moreover, MOFs MIL-53 ( $\mathrm{M}=\mathrm{Fe}, \mathrm{Cr}$, Al) were applied for methylene blue degradation under UV-Visible and visible light irradiation by Jing-Jing Du and $\mathrm{al}^{31}$..

The MOFs large specific surface area, the ease of synthesis, the low cost and diversified functionalities of MOFs have made these structures very attractive for numerous research 
fields. However, these materials existing as water-soluble powders, are generally of poor physical properties, instable, degradable by humid air, hard to manipulate, hydrolytically, chemically and thermally instable which limits their regeneration at the end of photocatalytic processes $^{32,33}$. Face to these considerations, many efforts have been made to enhance MOFs properties such as post-synthetic ligand exchange ${ }^{34}$, ion exchange ${ }^{35}$, addition of nanoparticles, biomolecule, clusters ${ }^{36,37}$ and associating MOFs with polymer inside or outside their pores. In fact, Li Peng et al, have synthesized a MOF/PDA(Polydopamine) composite by in-situ polymerization, with better water and $\mathrm{CO}_{2}$ adsorption properties compared to the initial $\mathrm{MOF}^{32}$. J.Pastore et al have also incorporated PAA (Poly (pyromellitic dianhydride-co-4,4'oxydianiline) into MOF structure by post-synthetic ligand exchange method which have improved their hydrolytically stability ${ }^{33}$. Furthermore, an hybrid composite HKUST-1@PAM (polyacrylamide) was synthesized by O'Neill et al using solvothermal methods or immersion in mother solution which have improved the resistance of the initial MOF against mechanical attrition and have enhanced the recovery and recyclability of crystalline MOF $^{38}$.

Herein, the first example of MOF/Polymer composites, synthesized by photopolymerization which is a green method realized at ambient temperature with high speed process, under harmless and low-priced LED irradiation source and without releasing volatile organic compounds was tested for the first time as photocatalyst for the photodegradation of Acid Black ${ }^{39}$. The exceptional materials obtained by photopolymerization exhibit the remarkable stability of the classical crosslinked polymers and retain the remarkable photocatalytic properties of MOFs, even after incorporation into polymers. By mean of this strategy, the chemical stability of Metal Organic Frameworks in water has been drastically improved, facilitating their use for photodegradation of pollutants by the easiness of manipulation and the facility of regeneration. Indeed, when incorporated into polymers, the unavoidable filtration or centrifugation step which are time-consuming methods for MOFs particles recovering can be advantageously avoided.

Therefore, upon UV-Lamp irradiation and without the addition of oxidative agents, the newly developed composites could maintain a highly photocatalytic activity for the Acid Black removal from water, even after 10 successive catalytic cycles. Such applications of immobilized MOFs for pollutant photodegradation has only been scarcely reported in the literature. A few examples exist in the literature. However, these catalysts were mostly used as powdered samples for pollutants catalytic degradation, and not incorporated into 
polymers ${ }^{40}$. The azo dye Acid Black was chosen as a model pollutant for monitoring MOF/Polymer composites efficiency because of its massive presence in textile industries effluent and due to its carcinogenic effects ${ }^{41,42}$. Degradation mechanism was also investigated by studying the effect of atmosphere or radical scavengers on the composite's photocatalytic activities. Finally, the photo-composites stability, surface structure, porosity, optical properties and regeneration were characterized by several analytical techniques including Thermogravimetric Analysis (TGA), Scanning Electron Microscopy (SEM), Transmission Electron Microscopy (TEM), Energy-dispersive X-ray analyses (EDX), Fourier-Transform Infrared Spectroscopy (FTIR), X- Ray Diffraction analysis (DRX), BET specific surface area, Atomic Force Microscopy (AFM), Dynamic Mechanical Analysis (DMA) and UV-Visible diffuse reflectance spectroscopy.

\section{Experimental section}

\subsection{MOFs synthesis}

MIL-53(Cr) was prepared as previously described ${ }^{43-45}$ with a slight modification. MIL-53(Cr) was hydrothermally synthesized from a mixture of chromium(III) nitrate, benzene-1,4dicarboxylic acid, hydrofluoric acid (HF) and $\mathrm{H}_{2} \mathrm{O}$. Reactants were introduced in a Teflon-lined steel autoclave, and the temperature was set at $493 \mathrm{~K}$ for 3 days. The light purple powder was recovered by filtration and then dispersed in $\mathrm{N}, \mathrm{N}$-dimethylformamide (DMF) at $373 \mathrm{~K}$ overnight to remove both the free terephthalic acid located inside the pores and the traces of recrystallized terephthalic acid by-product. Finally, the solid was dispersed at room temperature (RT) in a large excess of water to exchange the occluded $N, N$-dimethylformamide to get MIL-53(Cr) or $\mathrm{Cr}^{\prime \prime \prime}(\mathrm{OH})\left\{\mathrm{O}_{2} \mathrm{C}-\mathrm{C}_{6} \mathrm{H}_{4}-\mathrm{CO}_{2}\right\} . \mathrm{H}_{2} \mathrm{O}$.

HKUST-1 crystallizes under solvothermal ${ }^{46-48}$ conditions from a clear solution prepared by dissolving copper(II) nitrate hemi-(pentahydrate) and benzene-1,3,5-tricarboxylic acid in a mixture consisting of equal parts of $\mathrm{N}, \mathrm{N}$-dimethylformamide, ethanol and deionized water at $383 \mathrm{~K}$ for 12 hours. The solid was then scrubbed in N,N-dimethylformamide at RT to remove unreacted reagents and immersed in the appropriate activation solvent (dichloromethane) to exchange the occluded solvent for 3 days, during which the activation solvent was freshly replenished three times.

\subsection{Other chemicals compounds}


Trimethylolpropane triacrylate (TMPTA from Allnex) was selected as monomer for composite synthesis. Bis(4-tert-butylphenyl)iodonium hexafluorophosphate (lod or Speedcure 938), Phenyl bis(2,4,6-trimethylbenzoyl)phosphine oxide (BAPO or Speedcure BPO) was obtained from Lambson Ltd (UK) and were used as co-initiator and photoinitiator, respectively. Acid Black, 2,2,6,6-tetramethyl-1-piperidinyloxy (TEMPO) and EDTA (Ethylenediaminetetraacetic acid) were purchased from Sigma Aldrich. The 4-methoxyphenol (MEHQ) was obtained from Alfa Aesar.The chemical structures of the reagents used in this study are given by Figure 1.

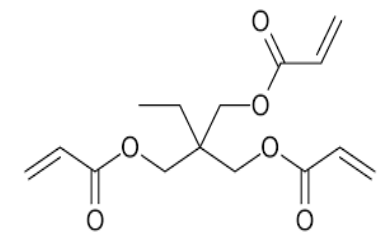

TMPTA

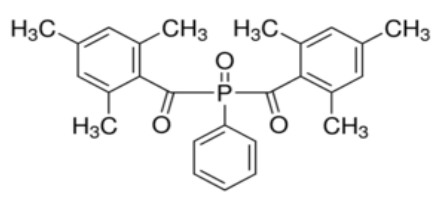

BAPO

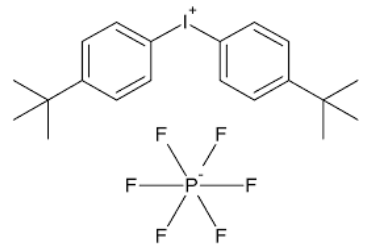

lodonium salt (IOD)<smiles></smiles>

Acid Black<smiles>O=C(O)CN(CCN(CC(=O)O)CC(=O)O)CC(=O)O</smiles>

EDTA

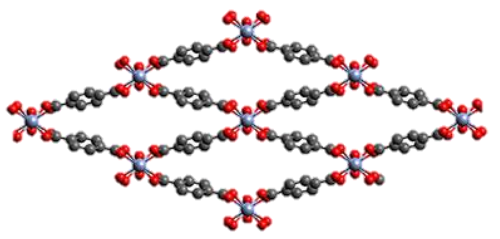

MIL-53(Cr)<smiles>CC1(C)CCCC(C)(C)N1[O]</smiles>

TEMPO

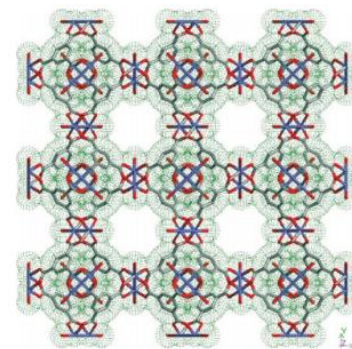

HKUST-1(Cu)

Figure 1 : Chemical structures of the main compounds used in this work.

\subsection{Photopolymerization experiments}

In this work, MIL-53(Cr) and HKUSTI-1(Cu) MOFs were incorporated in a acrylate monomer (TMPTA). The free radical polymerization experiments were carried out under air. The photosensitive resins containing TMPTA as the monomer, BAPO and the lodonium salt as the 
photoinitiating system were deposited in a mold to define the final shape of polymer or composite which is equal to $1.3 \mathrm{~mm}$. The evolution of the double bond content of TMPTA during the polymerization reaction was followed by real-time Fourier transform infrared spectroscopy at $4730 \mathrm{~cm}^{-1}$ for thick samples. Light Emitting Diodes LED@405 nm, $\mathrm{l}_{0}=100$ $\mathrm{mW} . \mathrm{cm}^{-2}$ was used as the irradiation source.

\subsection{Photocatalytic activity}

Photocatalytic performance of MIL-53(Cr)/polymer and HKUSTI-1(Cu)/polymer composites were evaluated by Acid Black removal from water. Acid Black samples were prepared by dissolving $15 \mathrm{mg}$ in $1 \mathrm{~L}$ of distilled water corresponding to an initial concentration of 24.25 $\mu \mathrm{mol} / \mathrm{L}$. The $\mathrm{pH}$ of the solution was equal to 5.9.

When experiments were carried out in the presence of MOF/polymer composites, the prepared composite in the form of pellet were added directly to the analysis cuvette in the presence of $4 \mathrm{~mL}$ of the Acid Black solution (15 ppm). In all cases, monitoring of the compound concentration in solution at $618 \mathrm{~nm}$ over time was performed using a JASCO V730 spectrophotometer. The solutions were analyzed in a spectrophotometer cell with $1 \mathrm{~cm}$ path length, and data were collected in absorbance mode.

The discoloration dye rate at different irradiation time was calculated by the following formula (eq.1):

$$
\text { Dye conversion }=\left(1-\frac{A b s t}{A b s t=0}\right) \times 100 \text { (eq.1) }
$$

Where $A b s t=0$ and $A b s t$ are the measured dyes absorbances before and after a given time ' $\mathrm{t}$ ' of irradiation.

\subsection{Composites stability}

\subsubsection{Stability in water}

Swelling experiments were realized by impregnating composites and polymer in water for $24 \mathrm{~h}$. The swelling ratio was calculated using the following formula (eq.2):

$$
\text { Swelling }=\left(\frac{W s}{W d}-1\right) \times 100 \quad(\text { eq. } 2)
$$

Where $W_{d}$ is the initial weight of polymer or composite and $W_{s}$ is the weight of swollen polymer or composite. 
Also, the dry extracts of the composites were calculated after the swelling experiments by drying them in an oven at $50^{\circ} \mathrm{C}$ for $1 \mathrm{~h}$. The dry extract was calculated using the following formula (eq.3):

$$
\text { Dry extract }=\frac{\mathrm{Wsd}}{\mathrm{Wd}} \times 100 \quad \text { (eq.3) }
$$

Where $W_{s d}=$ Weight of dried polymer or composite after swelling.

\subsubsection{Thermal stability}

The Thermogravimetric Analysis (TGA) was realized using TGA Mettler Toledo TGA/DSC3+. The experiments were carried out at temperatures ranging from $30^{\circ} \mathrm{C}$ to $800^{\circ} \mathrm{C}$ and were accessed at a heating rate of $10 \mathrm{~K} / \mathrm{min}$ under a dry airflow of $100 \mathrm{~mL} / \mathrm{min}$.

\subsection{Composites characterization}

\subsubsection{Morphological characterization}

For morphological characterization, JSM-7900F Scanning Electron Microscopy (SEM) from JEOL was used in this study. It was equipped with an annular detector from DEBEN for transmission images.

\subsubsection{Chemical analysis}

Energy-dispersive X-ray analyses were realized using the system QUANTAX double detector from Bruker.

\subsubsection{Composites structural characterization}

X-ray diffraction patterns were recorded using a Panalytical X'Pert PRO diffractometer equipped with a Cu X-ray tube (ICuKa $=0.1542 \mathrm{~nm}$ ) operating at $45 \mathrm{kV}$ and $40 \mathrm{~mA}$, and a X'Celerator detector. (A verifier avec Laure Michelin).

Fourier transform infrared absorption spectra were recorded on a thermo scientific is-50 FTIR spectrometer, using a diamond golden gate ATR accessory (GRASEBY) from SPECAC, in the range of $650-4000 \mathrm{~cm}^{-1}$.

\subsubsection{Composites surface properties and rigidity}


Surface properties and rigidity of the different composites were examined using Atomic Force Microscopy (AFM) techniques. AFM measurements were performed using a Bruker Multimode IV, with a Nanoscope V controller and an E "vertical" scanner (Bruker), by the Peak Force Quantitative Nanomechanical Mapping (PF-QNM, Bruker) method. PF-QNM is a contact AFM mode, based on the force-volume method. A calibration procedure was first followed. All quantitative measurements were carried out with NCLR cantilever (Nano World) with a spring constant of $48 \mathrm{~N} / \mathrm{m}$ and a resonance frequency of $190 \mathrm{kHz}$, a width of $38 \mu \mathrm{m}$ and a length of $225 \mu \mathrm{m}$. Thanks to the Sader method, the Actual spring constant was determined and found to be around $27 \mathrm{~N} / \mathrm{m}$. Then, the deflection sensitivity (around $32 \mathrm{~nm} / \mathrm{V}$ ) was measured on a sapphire surface. The Tip radius was calibrated against a polystyrene standard provided by Bruker. The measured value of the tip radius was $10 \mathrm{~nm}$. The Poisson's ratio was assumed to be equal to 0.3 . To get relevant results, the cantilever and the tip geometry are taking into account in the PF-QNM measurements. For all experiments, an area of $5 \mu \mathrm{m} \times 5$ $\mu \mathrm{m}(256 \times 256$ pixels at $0.6 \mathrm{~Hz})$ was taken at three different areas on the sample surface. (A verifier avec Aissam)

\subsubsection{Textural properties and porosity}

The textural characteristics of the different samples were determined from nitrogen adsorption/desorption at $77.35 \mathrm{~K}$ using micromeritics ASAP 2420 instrument. BET specific surface area and average pore diameter (Gurlich law) were calculated by using the standard Brunauer, Emmett, and Teller (BET) method based on adsorption data.

The samples were degassed at $25^{\circ} \mathrm{C}$ for 60 hours on degassing port and weighted. Then, the samples were degassed once again at $25^{\circ} \mathrm{C}$ for 4 hours on the analysis port to extract the trapped nitrogen. Analyses were realized with a reactor of the free volume to optimize the measurement and the free volumes were determined after analysis to avoid the pollution of the samples.

\subsubsection{Mechanical properties in bulk}

Dynamic storage modulus $G^{\prime}$ and dynamic loss modulus $G^{\prime \prime}$ of different synthesized composites were evaluated in order to determine their mechanical properties in bulk. The Dynamic Mechanical Analysis (DMA) was measured using DMA Mettler Toledo DMA861e. 


\subsubsection{Optical properties}

Due to the opaque nature of the composites, spectroscopy measurements were performed using the UV-Visible spectrophotometer (JASCO V-750) equipped with an integrating sphere.

\section{Results and discussion}

\subsection{Synthesis of MOF/Polymer composite by photopolymerization}

The photopolymerization technique was used to synthesize the different MOF/polymer composites by transforming the liquid-filled formulation containing TMPTA as the monomer and MOF as the fillers. This technique proved to be the most appropriate approach for incorporating MOFs into polymers since not heat was necessary to initiate the polymerization process thus avoiding the thermal degradation of MOFs that could occur during a classical thermal polymerization. The photopolymerization process is also extremely fast, enabling a facile access to composites. The obtained photopolymerization profiles for the free radical polymerization (FRP) of TMPTA are reported in Figure 2.

Figure $2(B)$, represents the TMPTA polymerization kinetics under visible irradiation in the presence of MOF HKUSTI-1(Cu) with different mass percentages. In fact, it is obvious that the polymerization performance slightly decreases (the final acrylate function conversions (AFC)) by adding the MOF to the initial TMPTA resin containing BAPO as the photoinitiator and the iodonium salt as the co-initiator. The results showed that the acrylate function double bond $(C=C)$ final percentage conversion reached in 60 seconds decreases from $82 \%$ to $80 \%, 77 \%$ and $71 \%$ in the presence of $0.5 \%, 1 \%$ and $2 \%$ of HKUSTI- $1(\mathrm{Cu})$, respectively. This could be explained by the inhibition of light penetration by the incorporated catalyst. Indeed, by increasing the mass percentage of MOF, the prepared formulations become less homogeneous and darker in color, acting in turn as in ternal filter. However, in the case of MIL-53(Cr)/Polymer composite (figure 2(A)), the encapsulation of this MOF into the polymer matrix did not significantly affect the final acrylate function conversions and the polymerization kinetics, except for the $2 \%$ MIL$53(\mathrm{Cr}) /$ polymer composite. In fact, by reaching this mass percentage, the prepared solution became less homogenous and more pigmented in color which provoked a decrease in the polymerization kinetics due to a reduced light penetration within the samples (figure 2 (A) (4)). 

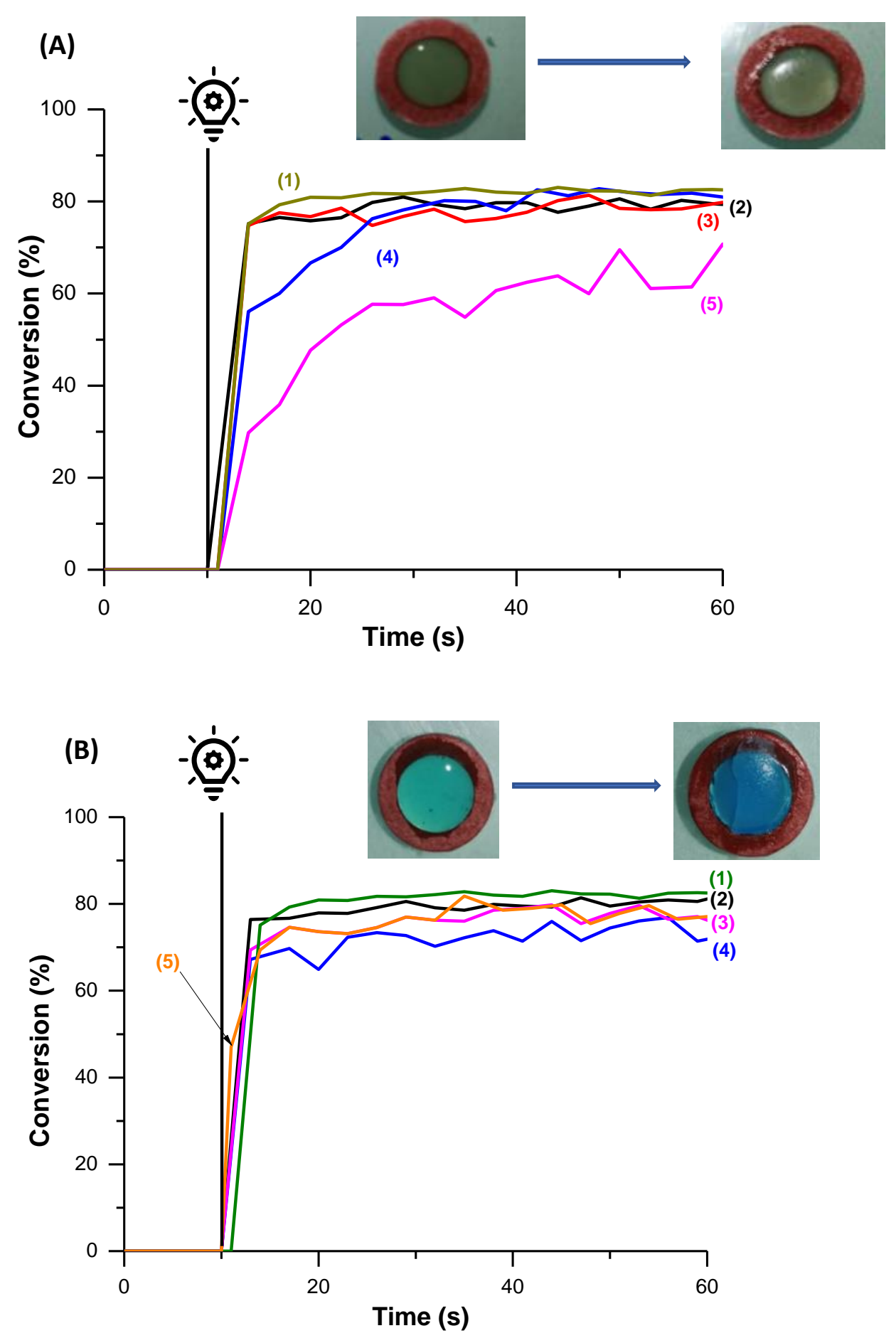
Figure 2: Photopolymerization profiles of acrylate functions (double bond conversion vs irradiation time) under air upon exposure to a LED@405 nm (A) in the presence of BAPO/lod/MIL-53(Cr) (1) $\quad(0.2 \% / 1 \% / 0 \% \quad(w / w / w)), \quad(2) \quad(0.2 \% / 1 \% / 0.5 \% \quad(w / w / w)), \quad$ (3) $(0.2 \% / 1 \% / 1 \%(w / w / w)),(4)(0.2 \% / 1 \% / 2 \%(w / w / w)),(5)(0.2 \% / 0 \% / 1 \%(w / w / w)) ;(B)$ in the presence of BAPO/lod/HKUST-1(Cu) (1) $(0.2 \% / 1 \% / 0(w / w / w)),(2)(0.2 \% / 1 \% / 0.5 \%(w / w / w))$, (3) $(0.2 \% / 1 \% / 1 \%(w / w / w))$, (4) $(0.2 \% / 1 \% / 2 \%(w / w / w))$ and $(5)(0.2 \% / 0 \% / 1 \%(w / w / w))$; thickness $=1.3 \mathrm{~mm}$; the irradiation starts at $\mathrm{t}=10 \mathrm{~s}$.

Figure 2 ((B), curves (2 and 5)) shows that the addition of the lodonium salt as the co-initiator for HKUSTI-1(Cu)/polymer composite synthesis is not essential for achieving high final monomer conversions. In fact, the acrylate function double bond $(\mathrm{C}=\mathrm{C})$ final conversion rate reached within 60 seconds with or without lodonium salt is equal to $77 \%$. However, during the synthesis of the MIL-53(Cr)/polymer composite, absence of iodonium salt in the photocurable resin resulted in a significant decrease of the photopolymerization rates, from $80 \%$ to $70 \%$ with and without iodonium salt after 60 seconds of irradiation at $405 \mathrm{~nm}$ (See Figure $2((A)$, curves (2 and 5$))$.

Addition of the iodonium salt in the formulations was carried out in order to be able to compare under the same conditions, the current results with those obtained in previous works on POMs/Polymer composites where the presence of this co-initiator had significantly improved the photopolymerization rates as well as the materials photocatalytic efficiency.

The photocatalytic activity of the different developed MOF/polymer composites will be discussed latter in section 3.4.

\subsection{MOF/Polymer composite stability}

Stability of photocatalysts is one of the most important parameters that has to be considered for an industrial application. Therefore, for a better application of our photocomposites in the photocatalytic field, stability of polymers in solutions and at high temperatures was examined.

\subsubsection{Stability in water}

Water is the most interesting solvent in heterogenous photocatalysis for practical environmental use. Therefore, in order to investigate MOF/polymer composites stability, 
swelling experiments were realized in this solvent. Dry extract ratio was also calculated to evaluate the monomer loss probability after polymerization.

Table 1. Acrylates Final Conversion (AFC \%), Swelling (\%) (in water) and dry extract (\%) of different synthesized MOF/polymer composites.

\begin{tabular}{lccc}
\hline & AFC (\%) & Swelling (\%) & Dry extract (\%) \\
\hline Polymer & 82 & $10 \pm 0.02$ & $100 \pm 2$ \\
\hline $\mathbf{0 . 5 \%}$ MIL-53(Cr)/polymer & 79 & $0 \pm 0.02$ & $100 \pm 2$ \\
\hline $\mathbf{1 \%}$ MIL-53(Cr)/polymer & 79 & $0 \pm 0.02$ & $100 \pm 2$ \\
\hline $\mathbf{2 \%}$ MIL-53(Cr)/polymer & 80 & $0 \pm 0.02$ & $100 \pm 2$ \\
\hline $\mathbf{0 . 5 \% ~ H K U S T I - 1 ( C u ) / p o l y m e r ~}$ & 80 & $0 \pm 0.02$ & $100 \pm 2$ \\
\hline $\mathbf{1 \% ~ H K U S T I - 1 ( C u ) / p o l y m e r ~}$ & 77 & $0 \pm 0.02$ & $100 \pm 2$ \\
\hline $\mathbf{2 \% ~ H K U S T I - 1 ( C u ) / p o l y m e r ~}$ & 71 & $0 \pm 0.02$ & $100 \pm 2$ \\
\hline
\end{tabular}

Based on the literature, the very low obtained swelling ratio of the different synthesized materials suggests a highly crosslinked acrylate network despite the presence of MOFs into the polymers ${ }^{49}$. Moreover, the calculated dry extract ratio indicates a low probability of monomer loss after the polymerization process which is in agreement with the final high acrylate polymerization rates. Hence, the obtained results shown in the Table 1 suggest an excellent stability of the composites in water.

\subsubsection{Thermal stability}

In order to evaluate the thermal stability of polymers and MOF/polymer composites, TGA analyses have been realized. Decomposition temperatures of the different synthesized materials are showed in Figure 3 and the results are gathered in Table 2. 
(A)

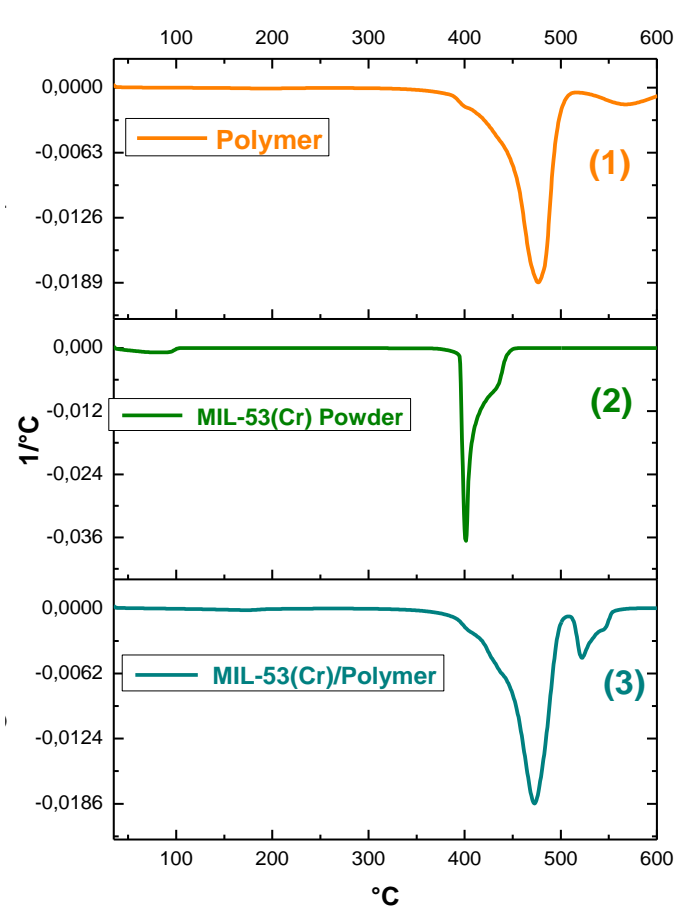

(B)

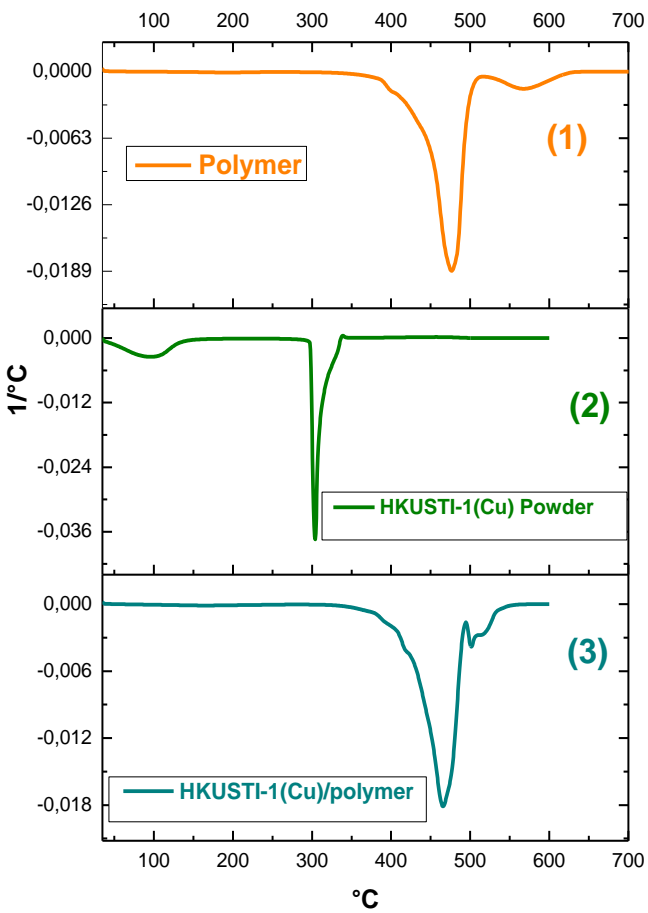

Figure 3 : Decomposition temperatures of (A) (1) Polymer; (2) MIL-53(Cr) powder and (3) 2\% MIL-53(Cr)/polymer composite. (B) (1) Polymer; (2) HKUSTI-1(Cu) powder and (3) 2\% HKUSTI1(Cu) /polymer composite.

TGA experiments have showed high and stable degradation temperatures for the different synthesized materials which is compatible for their applications in the photocatalytic field. In fact, MIL-53(Cr)/polymer and HKUSTI-1(Cu)/polymer composites are decomposed at $473^{\circ} \mathrm{C}$ and $467^{\circ} \mathrm{C}$, respectively. These temperatures are close to the polymer degradation temperature which is about $475^{\circ} \mathrm{C}$. Then, the MOFs incorporation into the polymer does not change this bulk property.

Table 2: Decomposition temperatures of the polymers, the crystals MOFs and the $2 \%$ MOF/polymer composites.

\begin{tabular}{lccccc}
\hline Material & Polymer & \multicolumn{3}{c}{ MOF Powder } & \multicolumn{2}{c}{ MOF/Polymer composites } \\
\cline { 2 - 6 } & & MIL-53(Cr) & HKUSTI-1(Cu) & MIL-53(Cr) & HKUSTI-1(Cu) \\
\hline $\begin{array}{l}\text { Decomposition } \\
\text { temperature }\left({ }^{\circ} \mathrm{C}\right)\end{array}$ & 476 & 401 & 303 & 473 & 467 \\
& & & & & \\
\end{tabular}




\subsection{MOF/Polymer composites characterization}

In order to verify the MOFs immobilization into the polymers and considering that heterogenous photocatalysis is a phenomenon occuring at the photocatalyst surface, morphological and structural characterizations of the developed composites were carried out. Furthermore, for practical applications, it is also important to investigate their optical and mechanical properties.

\subsubsection{Morphological and chemical characterization}

The developed MOF/polymer composites morphologies were characterized by Scanning Electron Microscopy (SEM) and Transmission Electron Microscopy (TEM). SEM images of the polymer used as a matrix for MOFs incorporation show a homogenous surface for the polymer film (See Figure 4 (i)).
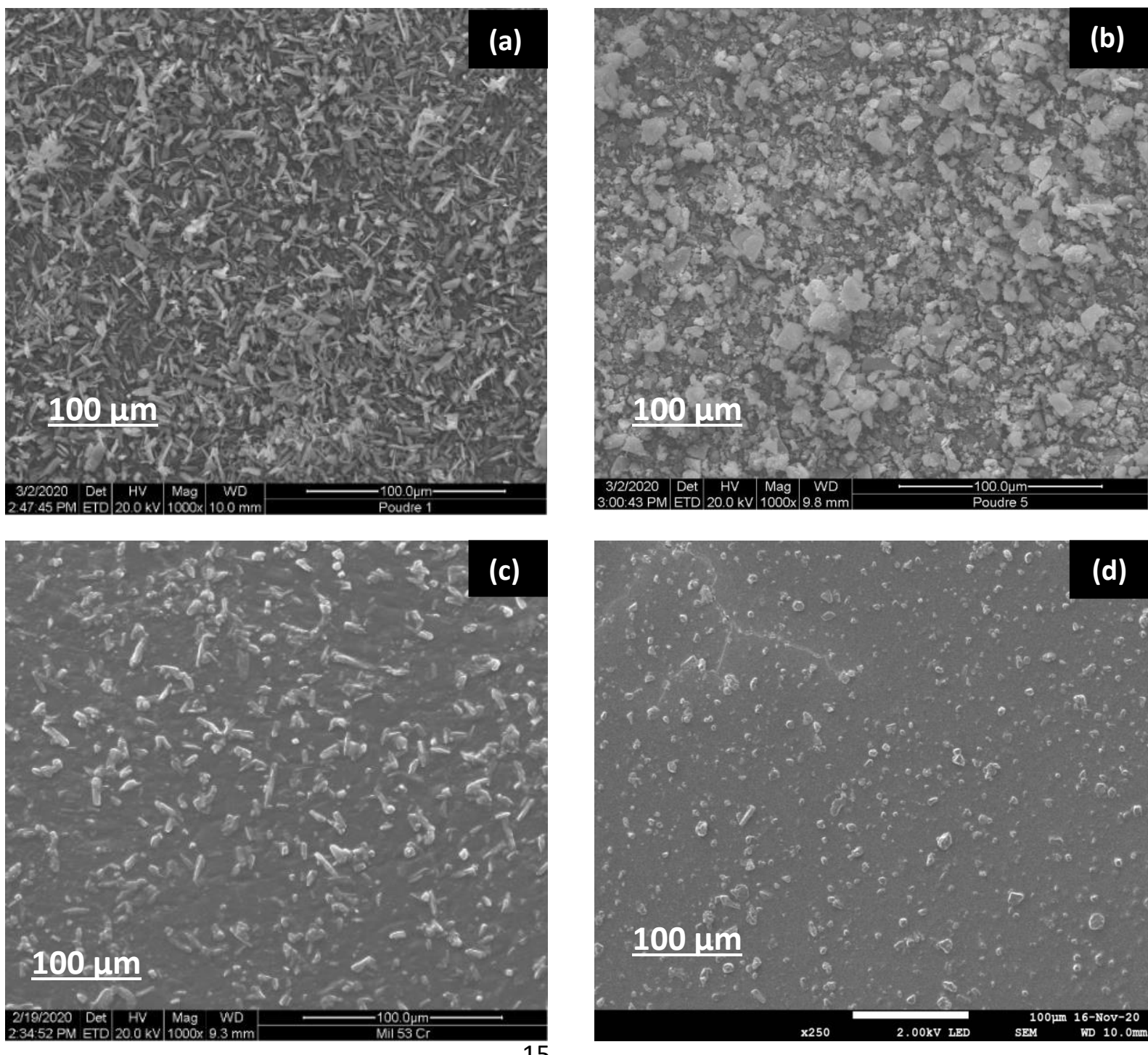

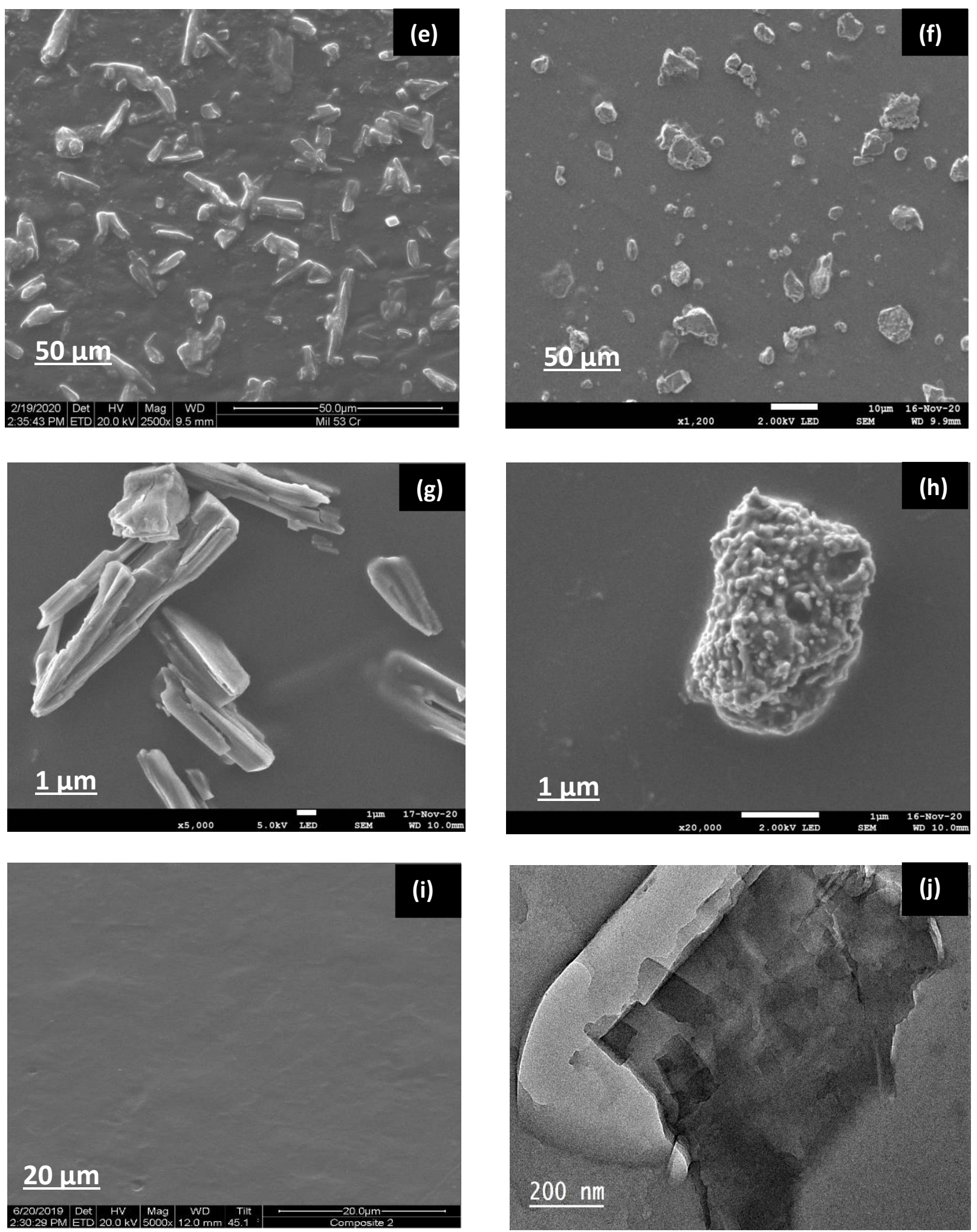


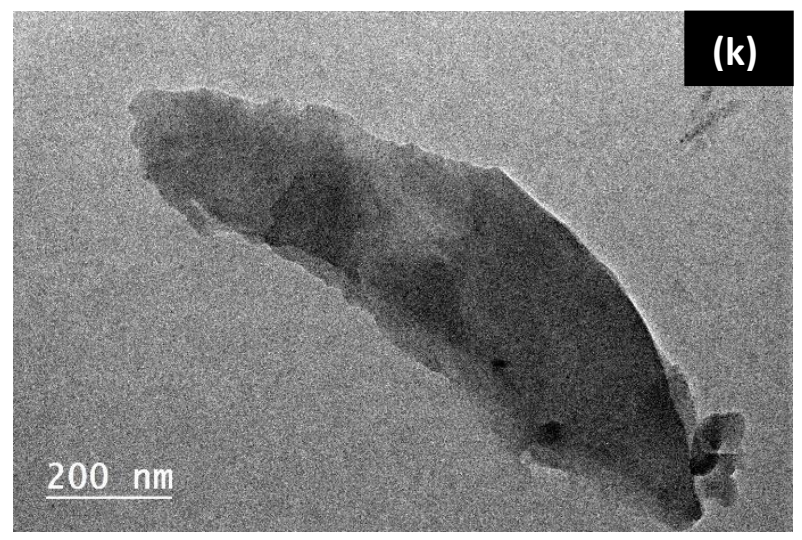

Figure 4 : SEM images of (a) MIL-53(Cr) powder; ( c, e, g ) 2\% MIL-53(Cr)/polymer composite at different scales; (e) HKUSTI-1(Cu) powder; ( $d, f, h$ ) 2\% HKUSTI-1(Cu)/polymer composite at different scales; ( $i$ ) polymer without MOF. TEM images of (j) $2 \%$ MIL-53(Cr)/polymer composite; (k) 2\% HKUSTI-1(Cu)/Polymer composite.

The SEM image of the crystalline MIL-53(Cr) (See Figure 4 (a)) shows micrometric rods like particles, which are also homogenously dispersed at the MIL-53(Cr)/polymer composite surface. Therefore, incorporation of this MOF into the polymer has probably not affected its structure (See Figures 4(a, c, e, g)). However, the HKUSTI-1(Cu)/polymer composite exhibits an heterogenous surface containing MOFs micrometric aggregates of different size ranging from $50 \mathrm{~nm}$ to $16 \mu \mathrm{m}$ (See Figures $4(\mathrm{~b}, \mathrm{~d}, \mathrm{f}, \mathrm{h})$ ). Furthermore, Figure $4(\mathrm{~h})$ presenting a zoom on a large HKUSTI-1(Cu) aggregate clearly demonstrates the presence of smaller aggregates. Also, Figures $4(\mathrm{j}, \mathrm{k})$ show TEM images of the MIL-53(Cr)/polymer and the HKUSTI$1(\mathrm{Cu}) /$ polymer composites indicating the presence of these catalysts at the polymer surface. Additionally, Energy Dispersive X-ray (EDX) analysis was realized in order to obtain additional informations about MOFs dispersion at the surfaces of the synthesized composites and to confirm the encapsulation of these catalysts into the polymers (See Figure 5). 

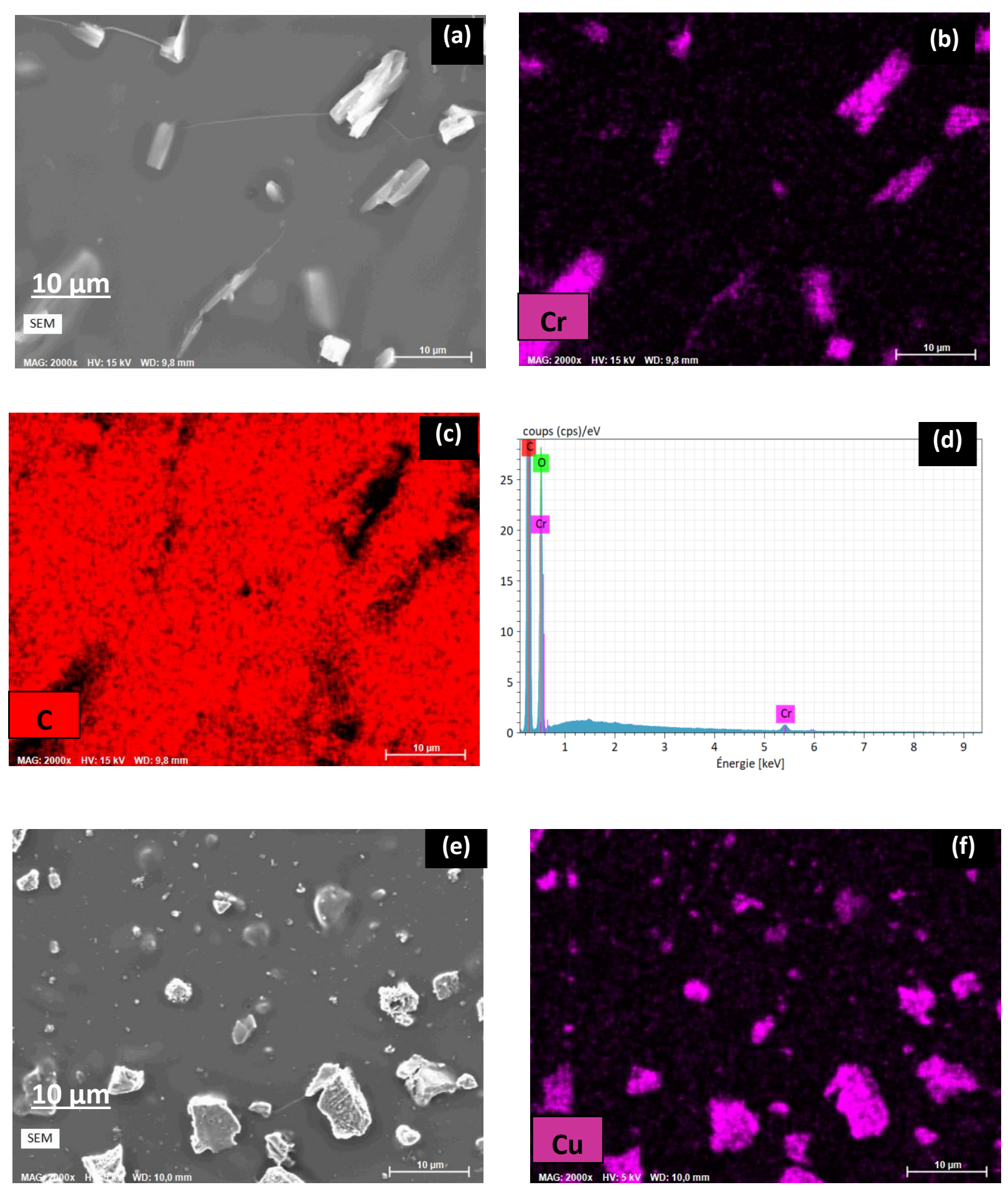

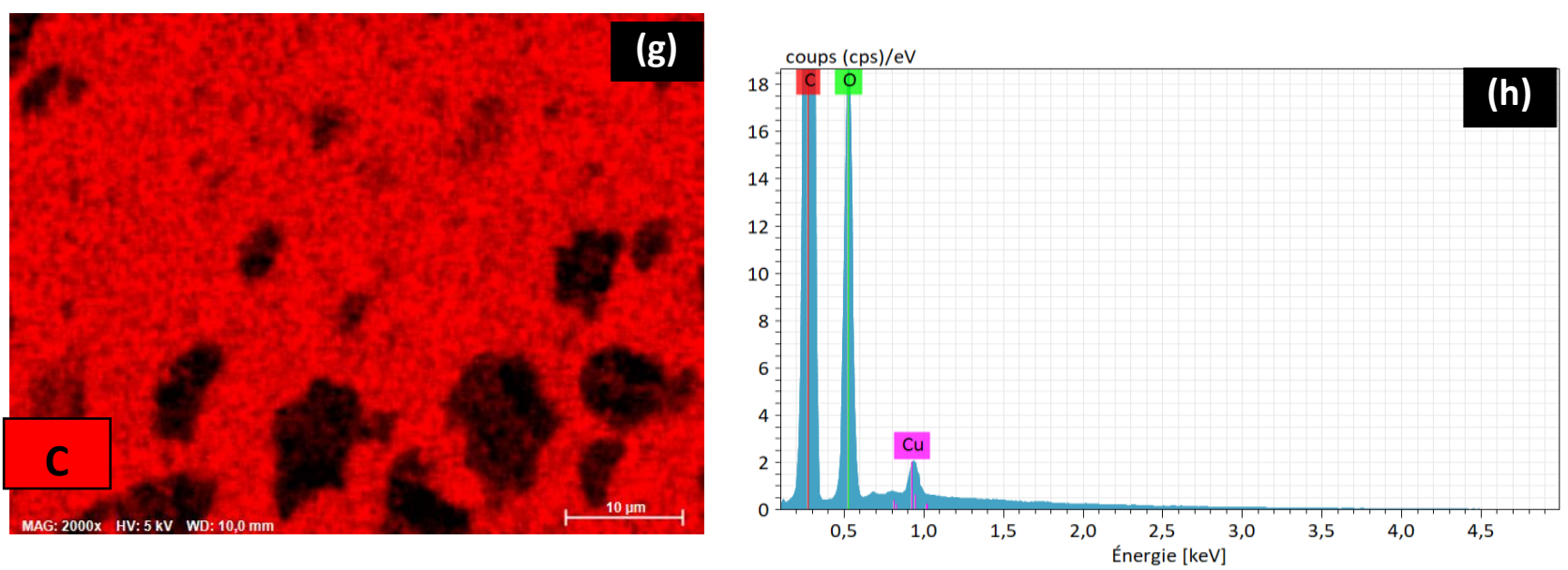

Figure 5 : SEM-EDX analysis of $(a, b, c, d) 2 \%$ MIL-53(Cr)/polymer composite; ( e, f, g, h) 2\% HKUSTI-1(Cu)/polymer composite.

Figure $5(a, b, c$ and e, f, g) images resulting from a coupling between SEM and EDX, confirm the MOF/polymer hybridization by the distribution of copper and chromium ions in the polymer network. EDX analysis (Figure $5(d, h)$ ) proves also the presence in the composite of copper and chromium belonging to MOF, carbon and oxygen coming from the TMPTA monomer and the catalyst.

In conclusion, TEM, SEM and EDX demonstrate that MOFs are clearly well incorporated into the polymer matrix by photopolymerization which is an easy synthesis method.

\subsubsection{Structural characterization}

In order to verify the MOFs incorporation into the polymer matrix, the different developed composites were qualitatively and structurally characterized by FTIR spectroscopy and by XRay Diffraction.

\subsubsection{Fourier-transform infrared spectroscopy}

Fourier-transform infrared (FTIR) spectra of MOFs, composites and polymer were acquired in the $600-4500 \mathrm{~cm}^{-1}$ region and the different spectra are shown in Figure 6. The MIL-53(Cr) FTIR 
spectrum (Figure 6, table 3) reveals five distinct bands at 3369, 1527, 1381, 750 and $925 \mathrm{~cm}^{-1}$. The broad peak, located at $3369 \mathrm{~cm}^{-1}$, is attributed to the stretching vibration of the $\mathrm{O}-\mathrm{H}$ bond from the water absorbed at the MIL-53(Cr) surface. The two thin and intense peaks, located at 1527 and $1381 \mathrm{~cm}^{-1}$ reflect the asymmetric and symmetrical vibrations of the $\mathrm{C}-\mathrm{O}$ bond of the ligand carboxyl group. The $\mathrm{C}-\mathrm{H}$ bond vibration of the benzene ring appears around $750 \mathrm{~cm}^{-}$ ${ }^{1}$ and the $\mathrm{Cr}-\mathrm{O}$ absorption peak is localized at around $925 \mathrm{~cm}^{-150}$. The five absorption bands characterizing the MOF MIL-53 $(\mathrm{Cr})$ are also present in the FTIR spectrum of the MIL-53 $(\mathrm{Cr})$ / Polymer composite in addition to those of the polymer. This proves the success of the MOF / polymer hybridization.

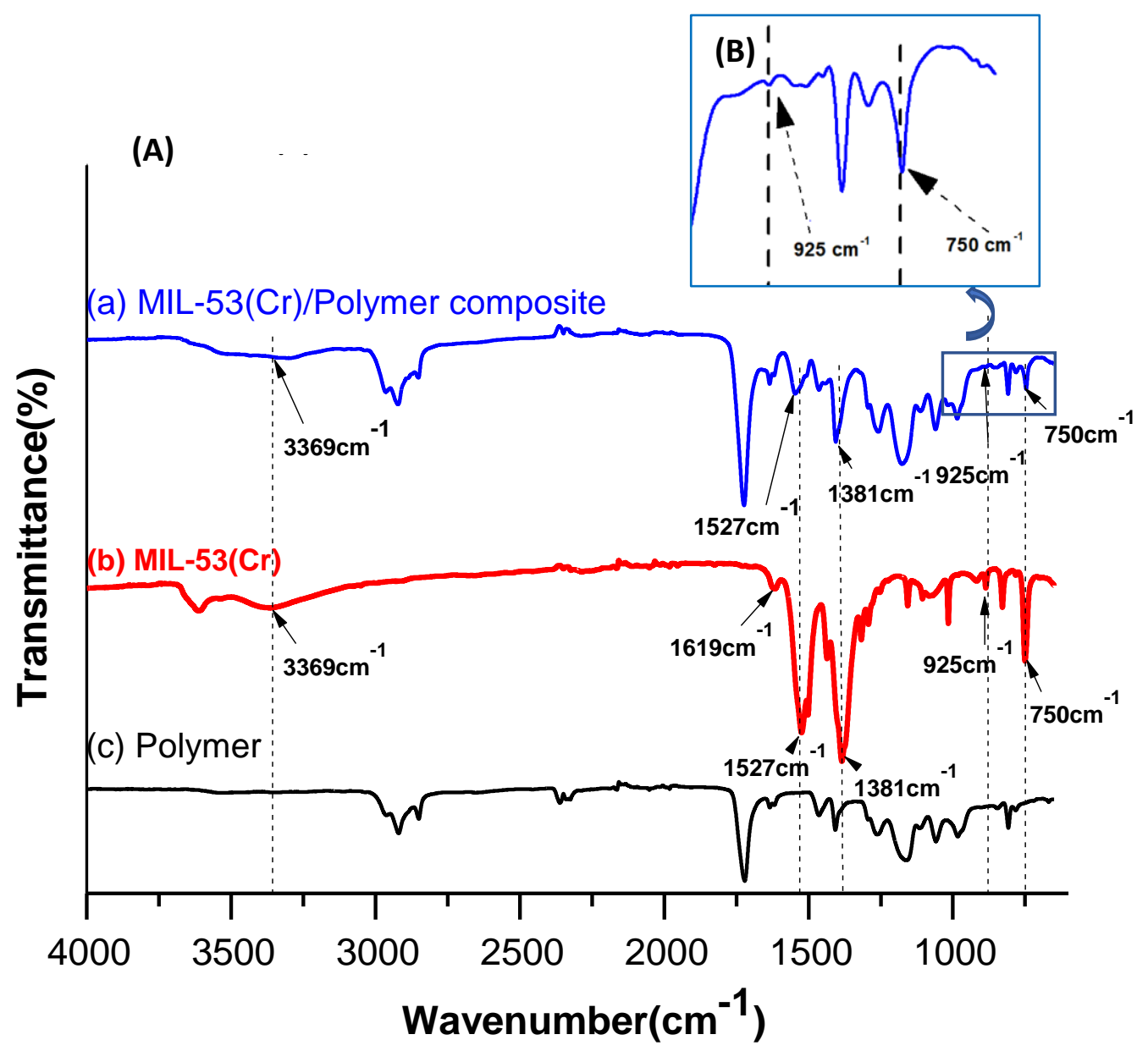

Figure 6 : (A) FTIR spectra of (a) the 2\% MIL-53(Cr)/polymer composite, (b) the crystalline MIL$53(\mathrm{Cr}),(\mathrm{C})$ the polymer and (B) Zoom-in of $750 \mathrm{~cm}^{-1}$ and $925 \mathrm{~cm}^{-1}$ peaks. 
Table 3 : FTIR characterization of MIL-53(Cr) MOF.

\begin{tabular}{llclll}
\hline & $\begin{array}{l}-\mathrm{OH} \\
\text { (stretching } \\
\text { vibration) }\end{array}$ & $\begin{array}{l}\text { C-O (asymmetric } \\
\text { stretching } \\
\text { vibration) }\end{array}$ & $\begin{array}{l}\text { C-O (symmetric } \\
\text { stretching } \\
\text { vibration) }\end{array}$ & $\begin{array}{l}\text { C-H the } \\
\text { benzene ring }\end{array}$ & Cr-O \\
\hline $\begin{array}{l}\text { Wavenumber } \\
\left(\mathrm{cm}^{-1}\right)\end{array}$ & 3369 & 1527 & 1381 & 750 & 925 \\
\hline
\end{tabular}

Figure 7 displays the FTIR spectrum of $2 \%$ HKUSTI-1(Cu)/polymer composite, HKUSTI-1(Cu) crystalline and the polymer. Table 4 shows the wavenumber of the most important HKUSTI$1(\mathrm{Cu})$ functional groups. The peak at $729 \mathrm{~cm}^{-1}$ is attributed to the $\mathrm{Cu}-\mathrm{O}$ bond $\mathrm{d}^{51,52}$. The $\mathrm{C}=\mathrm{C}$ stretching vibration of benzene is characterized by a strong band at $1370 \mathrm{~cm}^{-151,53}$. Moreover, bands arounds 1450 and $1644 \mathrm{~cm}^{-1}$ represent C-O symmetric and asymmetric stretching vibrations, respectively ${ }^{51,53}$. Also, the wide band between 3000 and $3500 \mathrm{~cm}^{-1}$ corresponds to $-\mathrm{OH}$ water stretching vibration ${ }^{51}$. Due to the low HKUSTI-1(Cu) mass percentage incorporated into the polymer, the characteristic peaks of this MOF were hardly distinguished from those of the polymer matrix.

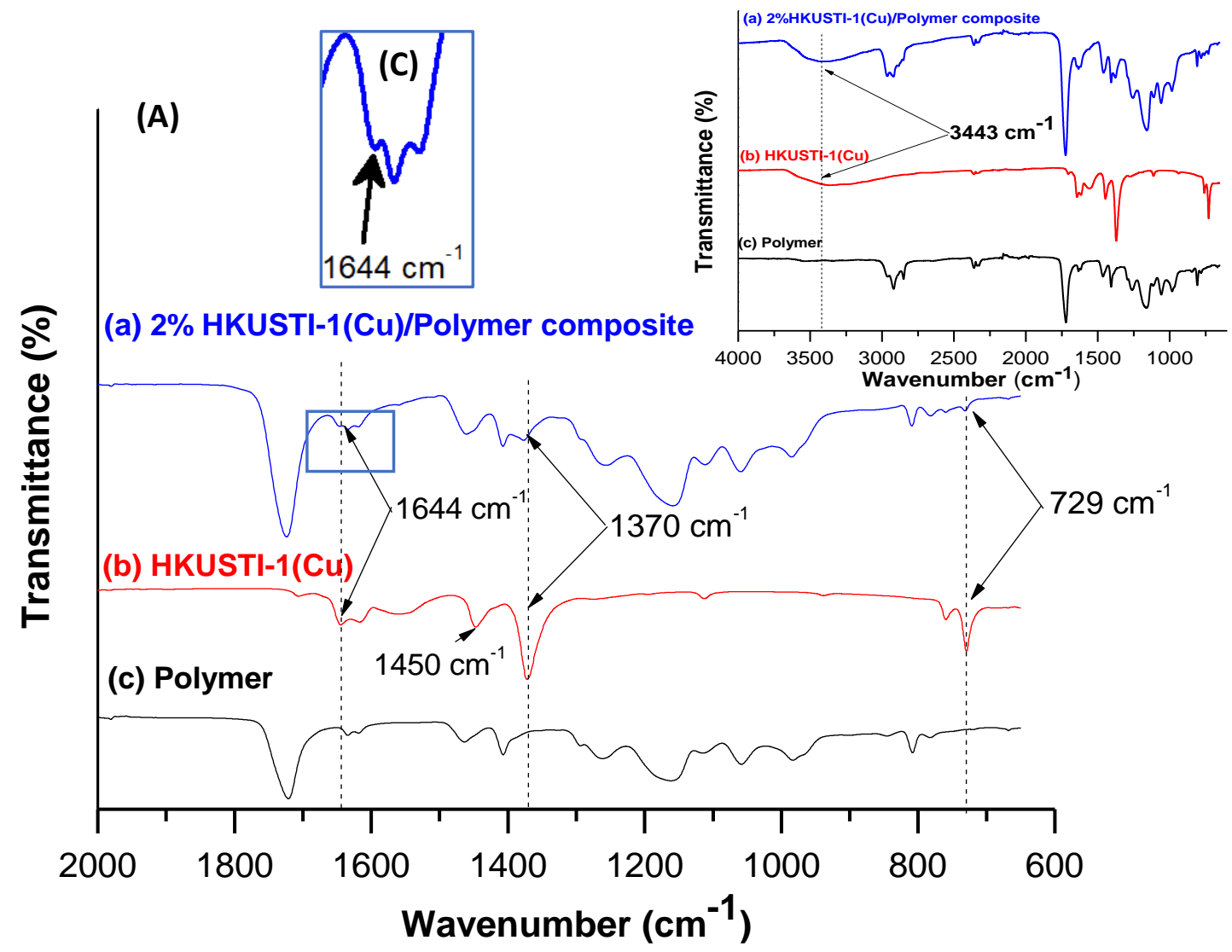

Figure 7 : FTIR spectra of (a) 2\% HKUSTI-1(Cu)/polymer composite, (b) the Crystalline HKUSTI$1(\mathrm{Cu})$ and (c) the polymer between (A) $2000 \mathrm{~cm}^{-1}-600 \mathrm{~cm}^{-1}$ and (B) $4000 \mathrm{~cm}^{-1}-600 \mathrm{~cm}^{-1}$. (C) Zoom-in of $1644 \mathrm{~cm}^{-1}$ peak. 
Table 4 : FTIR characterization of HKUSTI-1(Cu) MOF.

\begin{tabular}{llcccc}
\hline & $\begin{array}{l}-\mathrm{OH} \\
\text { (stretching } \\
\text { vibration) }\end{array}$ & $\begin{array}{l}\text { C-O (asymmetric } \\
\text { stretching } \\
\text { vibration) }\end{array}$ & $\begin{array}{l}\text { C-O (symmetric } \\
\text { stretching } \\
\text { vibration) }\end{array}$ & $\begin{array}{l}\text { C=C (Stretching } \\
\text { vibration of the } \\
\text { benzene ring) }\end{array}$ & Cu-O \\
\hline $\begin{array}{l}\text { Wavenumber } \\
\left(\mathrm{cm}^{-1}\right)\end{array}$ & 3443 & 1644 & 1450 & 1370 & 729 \\
\hline
\end{tabular}

\subsubsection{X-Ray Diffraction (XRD)}

In order to deeply analyze the molecular structure of composites and to get further insight on the structural variations of the catalyst after its incorporation into the polymer matrix, XRD analyses were carried out (See Figure 8).

(A)

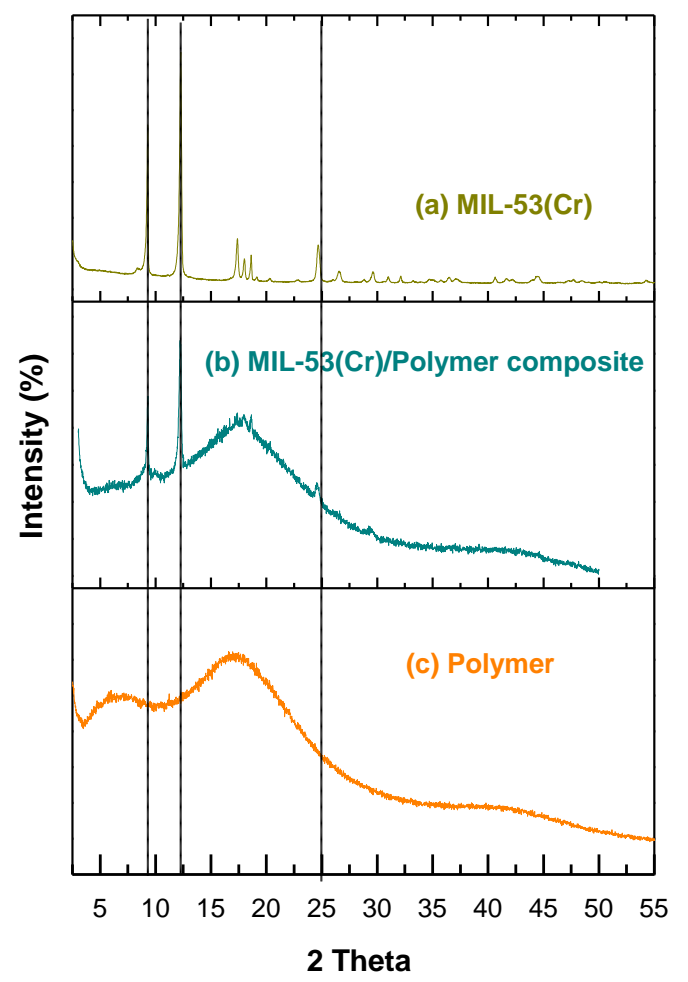

(B)

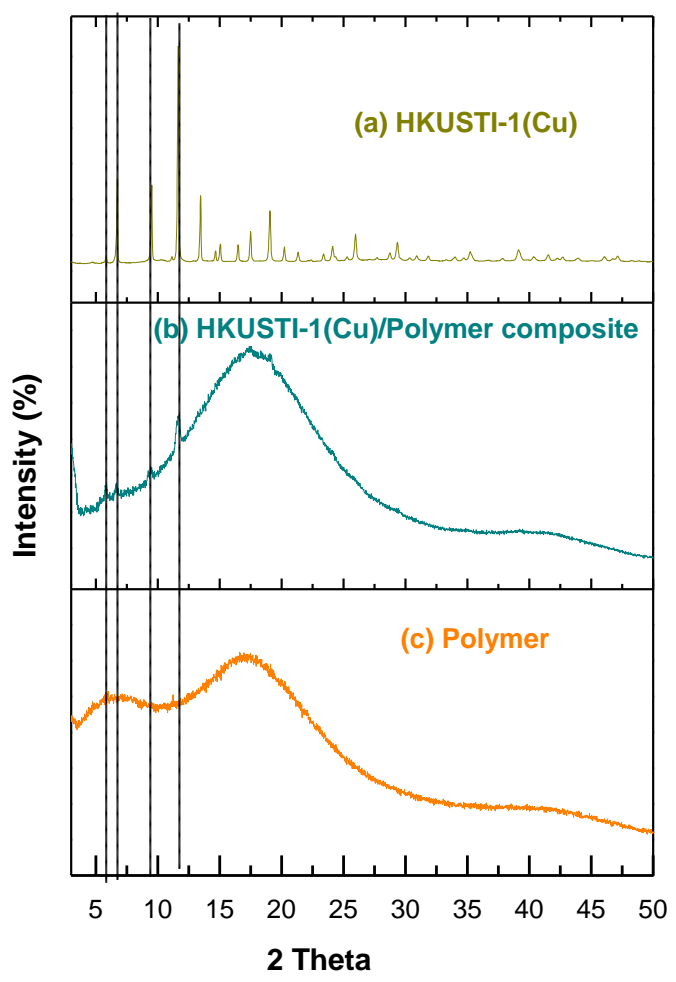

Figure 8 : XRD analysis of (A) (a) MIL-53(Cr), (b) 2\% MIL-53(Cr)/polymer composite, (c) Polymer and (B) (a) HKUSTI-1(Cu), (b) 2\% HKUSTI-1(Cu)/polymer composite, (c) Polymer.

The crystallite MIL-53 (Cr) diffractogram (See Figure $8(\mathrm{~A}(\mathrm{a})$ ) corresponds to that of MIL-53 (It) or $\mathrm{Cr}^{\prime \prime \prime}(\mathrm{OH}) \cdot\left\{\mathrm{O}_{2} \mathrm{C}-\mathrm{C}_{6} \mathrm{H}_{4}-\mathrm{CO}_{2}\right\} . \mathrm{H}_{2} \mathrm{O}$ already reported by the literature ${ }^{44}$. This latter is represented by a three-dimensional structure formed by chromium (III) octahedra and terephthalate ions, creating a three-dimensional framework with a one-dimensional pore channel system 
containing water molecules interacting with oxygen atoms or hydroxyl groups of the inorganic network through hydrogen bonds (figure 1$)^{44}$.

The crystal structure of $\left[\mathrm{Cu}_{3}(\mathrm{TMA})_{2}\left(\mathrm{H}_{2} \mathrm{O}\right)_{3}\right]_{n}$ known as HKUSTI-1(Cu) was previously reported by Chui et $\mathrm{al}^{46}$. and Schlichte et $\mathrm{a}^{54}$. This Framework forms face-centered-cubic crystals with an interconnecting three-dimensional system of large pores holding additional water molecules ${ }^{46}$.

The main XRD peaks of the synthesized MIL-53(Cr)/polymer composites are identical to that of the crystalline MIL-53(Cr) powder indicating no crystallinity changes during the photopolymerization process. Moreover, the peaks on the XRD patterns of HKUSTI$1(\mathrm{Cu}) /$ polymer are indicative of the HKUSTI-1(Cu) crystals presence.

However, it can be observed that the MOF peaks intensities decrease by its incorporation into the polymer matrix which could be attributed to TMPTA filling the pores, to the low MOF mass percentage used equal to $20 \mathrm{mg}$ dispersed into $1 \mathrm{~g}$ of monomer or to the arbitrary dispersal of MOFs crystals inside the polymer ${ }^{55}$.

\subsubsection{Surface properties and porosity}

\subsubsection{BET analysis}

Heterogenous photocatalysis is a phenomenon that occurs on the photocatalyst surface, therefore, in order to understand the composites catalysis behavior, it was important to evaluate their BET surfaces area, the adsorption average pore width and the total area in pores. Results are reported in Table 5.

Table 5 : BET surface area and adsorption average pore width of the different MOF/polymer based TMPTA composites and of the polymer.

\begin{tabular}{lccc}
\hline & $\begin{array}{c}\text { BET surface area } \\
\left(\mathbf{m}^{2} \cdot \mathrm{g}^{-1}\right)\end{array}$ & $\begin{array}{c}\text { Adsorption average } \\
\text { pore width }(\mathbf{n m})\end{array}$ & $\begin{array}{c}\text { Total area in } \\
\text { pores }\left(\mathbf{m}^{\mathbf{2}} \cdot \mathbf{g}^{-1}\right)\end{array}$ \\
\hline TMPTA polymer & 9.3 & 4.3 & 6.3 \\
\hline HKUSTI-1(Cu) & $1944^{56}$ & - & - \\
\hline MIL-53(Cr) & $1350^{56}$ & - & - \\
\hline $\mathbf{0 . 5 \%}$ MIL-53(Cr)/Polymer & 5.6 & 4.4 & 1.9 \\
\hline
\end{tabular}




\begin{tabular}{lccc}
\hline 1\% MIL-53(Cr)/Polymer & 4 & 4.2 & 1.1 \\
\hline 2\% MIL-53(Cr)/Polymer & 1.7 & 5.2 & 0.7 \\
\hline 0.5\%HKUSTI1(Cu)/Polymer & 1 & 8.8 & 0.4 \\
\hline 1\%HKUSTI-1(Cu)/Polymer & 2.6 & 7 & 0.8 \\
\hline 2\%HKUSTI-1(Cu)/Polymer & 1.9 & 8.1 & 0.6 \\
\hline
\end{tabular}

For the neat polymer, the pore size distribution according to the Density Functional Theory (DFT) showing the presence of a large porosity with a maximum value of about $4.8 \mathrm{~nm}$ was reported in our previous works ${ }^{57}$. According to Table 5, the incorporation of MOFs into the polymer induced a significant decrease in its BET surface $\left(9.3 \mathrm{~m}^{2} \cdot \mathrm{g}^{-1}\right)$, pore width $(4.3 \mathrm{~nm})$ and total area in pores $\left(6.3 \mathrm{~m}^{2} \cdot \mathrm{g}^{-1}\right)$. In fact, polymer BET surface area is diminished to 5.6, 4 and $1.7 \mathrm{~m}^{2} \cdot \mathrm{g}^{-1}$ and to $1,2.6$ and $1.9 \mathrm{~m}^{2} \cdot \mathrm{g}^{-1}$ by adding $0.5 \%, 1 \%$ and $2 \%$ of MOF MIL-53(Cr) and HKUSTI-1(Cu), respectively. Similarly, incorporating MOFs into the polymer have significantly decreased the total area in pores to values ranging between 1.9 and $0.4 \mathrm{~m}^{2} \cdot \mathrm{g}^{-1}$. Such a decrease in BET surface area and total pores volume could be explained by the fact that incorporated MOFs are confined with the polymer channels as shown in Figure 5 (b, c, f, g), which blocks the polymer mesopores.

Remarkably, HUKSTI-1(Cu) and MIL-53(Cr) lose their porosity when immobilized into the polymer matrix. Indeed, their BET surface area was reduced from 1944 and $1350 \mathrm{~m}^{2} \cdot \mathrm{g}^{-1}$ to 1.7 and $1.9 \mathrm{~m}^{2} \cdot \mathrm{g}^{-1}$ in the case of $2 \% \mathrm{MIL}-53(\mathrm{Cr}) /$ polymer and $2 \% \mathrm{HKUSTI}-1(\mathrm{Cu}) /$ polymer composites synthesis. Such results could be explained by polymer blocking the access to the MOFs pores or by the penetration of TMPTA resin chains inside the MOFs cavities ${ }^{50,58}$. This phenomenon was previously observed by Wickenheisser et al who developed MIL101(Cr)@NIPAM (poly(N-isopropyl acrylamide)HIPE) ${ }^{59}$ and by Schwab et al during the synthesis of a polyHIPE enclosing HKUSTI MOFs ${ }^{60}$.

\subsubsection{Surface topology by AFM}

In order to obtain further details of the surface structure such as roughness, topology of HKUSTI-1(Cu)/polymer composite, MIL-53(Cr)/polymer composite and the TMPTA polymer were characterized by Atomic Force Microscopy (AFM) with the Peak-Force QNM imaging. Figure 9 shows the obtained topological images. 

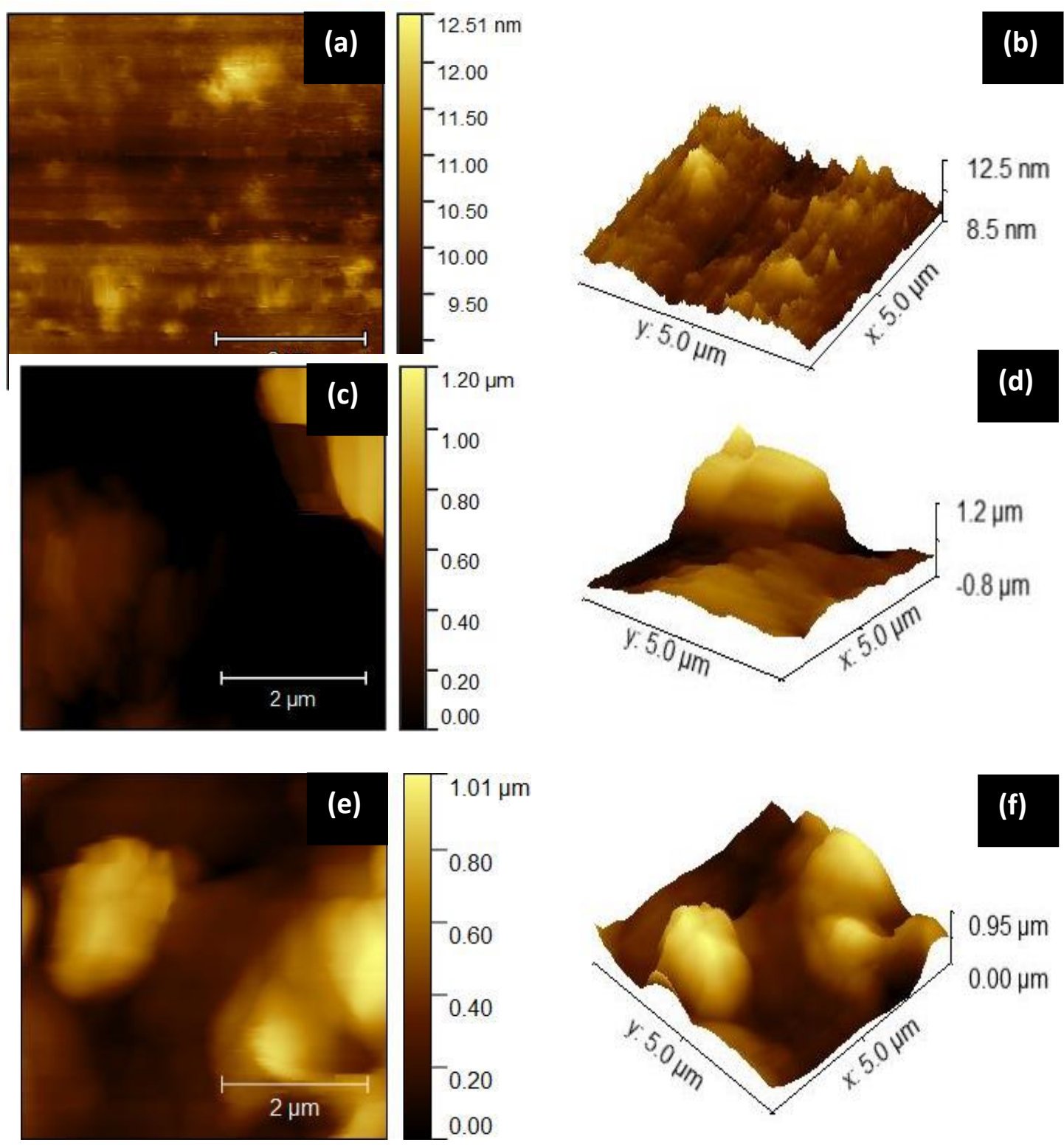

Figure $9: 2 \mathrm{D}$ and 3D AFM topology images of $(a, b)$ the polymer without MOF, $(c, d)$ the $1 \%$ MIL-53(Cr)/polymer composite and (e, f) the 1\% HKUSTI-1(Cu)/polymer composite.

Figure $9(a, b)$ presents AFM images recorded topology of the polymer exhibiting a relatively rough surface with a roughness average value equal to $5 \mathrm{~nm}$. This rugosity caused by the presence of edges and grooves could explain the polymer porosity obtained by BET surface area analysis (table 5). However, in the case of MIL-53(Cr)/polymer and HKUSTI$1(\mathrm{Cu}) /$ polymer composites, a much higher surface rugosity was observed ranging from $[0-1.20$ $\mu \mathrm{m}$ ] (figure 9 (c, d, e, f) with roughness average values of $306 \mathrm{~nm}$ and $195 \mathrm{~nm}$, respectively. The observed difference of rugosity between the polymer and MOF/polymer composites is 
certainly attributable to the presence of MIL-53(Cr) and HKUSTI-1(Cu) MOFs at the polymer surface (see EDX data (figure 5)).

Figure 9 (c) corresponds to a 2D image recorded over an area of $5 \mu \mathrm{m} \times 5 \mu \mathrm{m}$ of the HKUSTI$1(\mathrm{Cu}) /$ polymer composite. It reveals the presence of cylindric micrometry MOF aggregates at the polymer surface which is in agreement with the composite SEM images (Figure 4(d, f, h)). In order to ameliorate the practical applications of our photocatalysts for the wastewater treatment, MOFs-based polymers should be characterized by good mechanical properties allowing their facile reuse and collect. Therefore, influence on the mechanical properties of the incorporation of MOFs into TMPTA-based polymers was studied.

\subsubsection{Mechanical properties}

Mechanical properties of the synthesized composites were investigated by AFM (Peak-Force QNM imaging mode). Figure 10 shows the recorded topology of the elastic modulus on the surface of the MIL-53(Cr)/polymer and HKUSTI-1(Cu)/polymer composites.
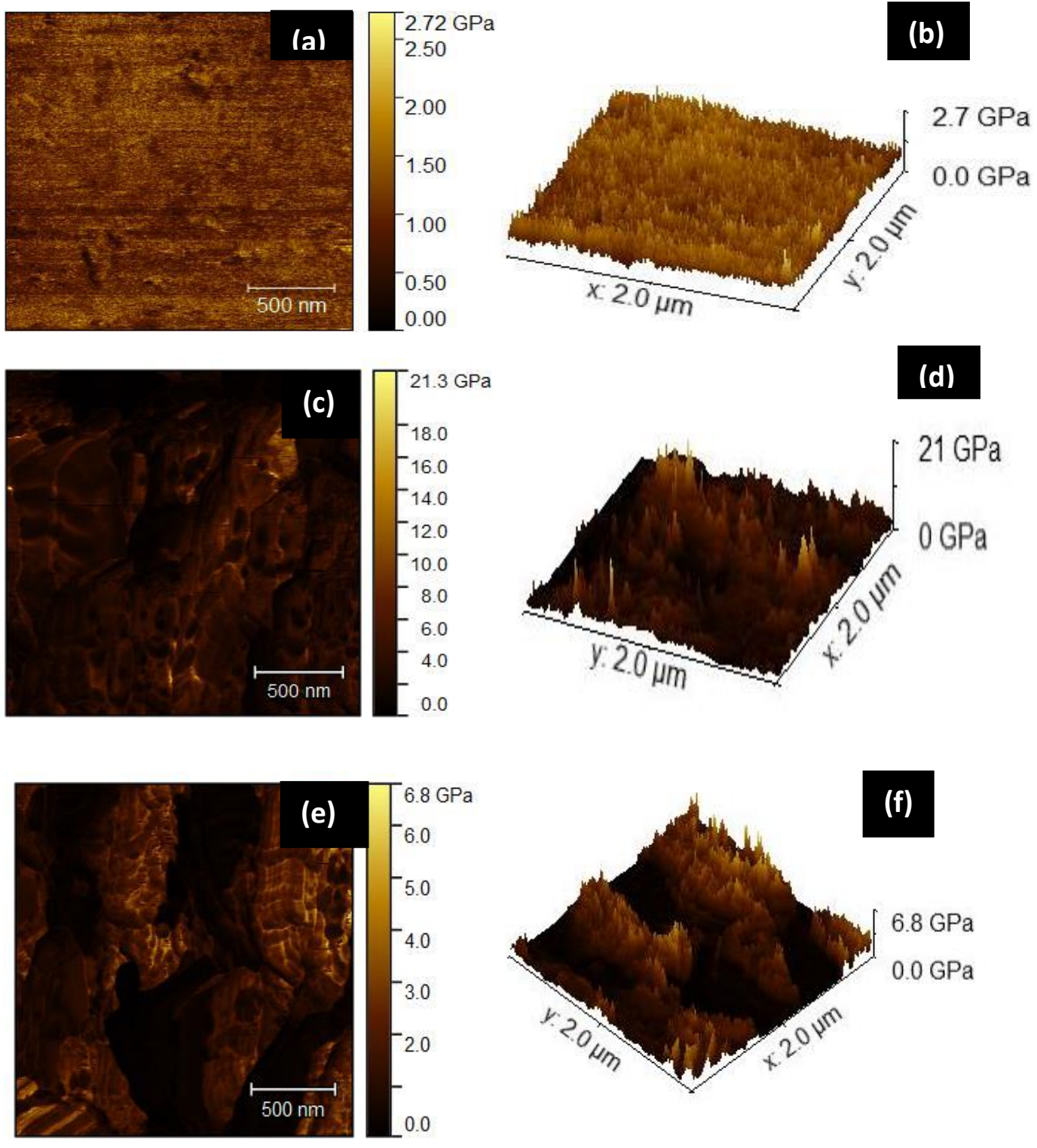
Figure $10: 2 \mathrm{D}$ and 3D elastic modulus maps of $(a, b)$ pure TMPTA based polymer, $(c, d) 1 \%$ MIL-53(Cr)/polymer composite and (e, f) 1\% HKUSTI-1(Cu)/Polymer.

The elastic resistance to AFM indentation reflects the rigidity of the polymer or the composite network. Compared to the polymer elastic modulus ranging from [0 - 2.7 GPa] with a mean value of $1.4 \mathrm{GPa}$, the MIL-53(Cr)/polymer and HKUSTI-1(Cu)/Polymer composites showed a higher elastic modulus ranging from [0 - 21.3GPa] and [0-6.8GPa] with a mean value of 2.5 $\mathrm{GPa}$ and $1 \mathrm{GPa}$, respectively. This enhancement and deterioration of polymers rigidity is attributed to the MIL-53(Cr) and HKUSTI-1(Cu) crystals presence into the polymer.

Additionally, Figure 11 shows the elastic modulus distribution of the polymer, the $1 \%$ HKUSTI$1(\mathrm{Cu}) /$ polymer composite, the $1 \% \mathrm{MIL}-53(\mathrm{Cr}) /$ polymer composite as well as their gaussian fit.

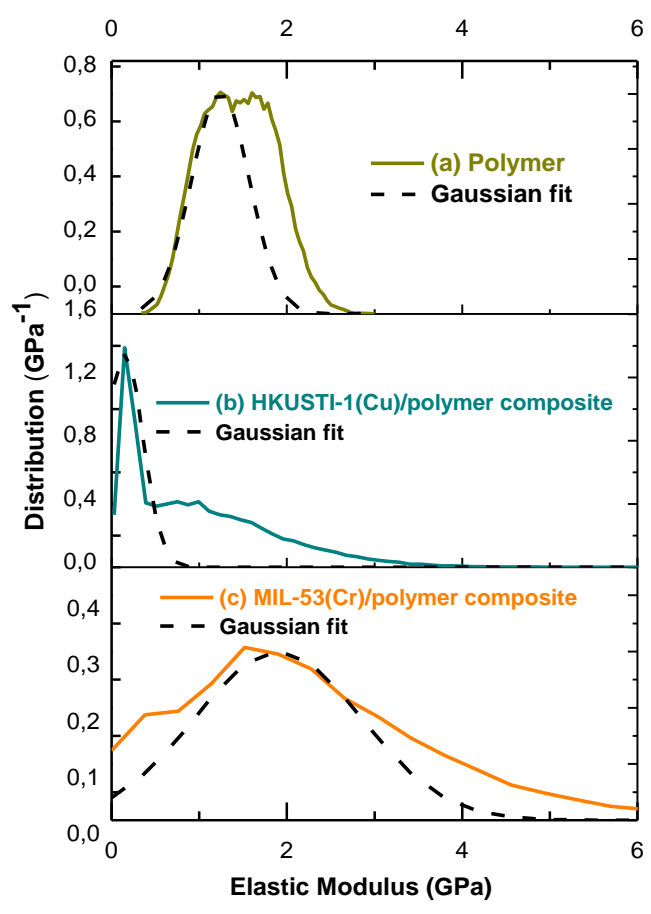

Figure 11 : Elastic Modulus distribution of (a) the pure TMPTA based polymer, (b) 1\% HKUSTI1(Cu)/polymer, (c) 1\%MIL-53(Cr)/polymer and their gaussian fit (---).

The curves presented in Figure 11 show an inhomogeneity in the normal Gaussian distribution for the elastic modulus in each sample and illustrate clearly that the presence of the MOFs into the polymer affects it rigidity.

In order to obtain further mechanical informations, the bulk mechanical properties of the composites were evaluated by Dynamic Mechanical Analysis (DMA) experiments. The 
obtained values of dynamic storage modulus $\mathrm{G}^{\prime}$ and dynamic loss modulus $\mathrm{G}^{\prime \prime}$ at $25^{\circ} \mathrm{C}$ are presented in Table 6.

Table 6: Dynamic storage modulus $\left(G^{\prime}\right)$, dynamic loss modulus $\left(G^{\prime \prime}\right)$ at $25^{\circ} \mathrm{C}$ and Elastic Modulus of TMPTA based polymer, 1\% MIL-53(Cr)/polymer and 1\% HKUSTI-1(Cu)/polymer composites.

\begin{tabular}{cccc}
\hline $\begin{array}{c}\text { Composition } \\
\text { Polymer }\end{array}$ & $\begin{array}{c}\text { Dynamic storage } \\
\text { modulus G'(MPa) }\end{array}$ & $\begin{array}{c}\text { Dynamic loss } \\
\text { modulus G' (MPa) }\end{array}$ & $\begin{array}{c}\text { Elastic Modulus } \\
\text { (GPa) }\end{array}$ \\
\hline 1\%MIL-53(Cr)/Polymer & 100 & 20 & 1.4 \\
\hline 1\%HKUSTI-1(Cu)/Polymer & 162 & 12 & 2.5 \\
\hline
\end{tabular}

Interestingly, the dynamic storage modulus $G^{\prime}$ is greater than the dynamic loss modulus $G^{\prime \prime}$ in the case of the polymer and the synthesized MOF/polymer composites, suggesting a rigid character of these materials which is in agreement with the low swelling degree and the high crosslinking density of the polymer network (Table 1). In bulk, $\mathrm{G}^{\prime}$ was increased from 100 to $131 \mathrm{MPa}$ and 162 by MIL-53(Cr) and HKUSTI-1(Cu) crystals incorporation into the polymer matrix, respectively. Therefore, neat TMPTA polymer bulk properties were ameliorated by its association with these two MOFs presence. Remarkably, HKUSTI-1(Cu) encapsulation into the polymer didn't affect its mechanical surface and bulk properties in the same way. Presence of this MOF ameliorated the bulk rigidity of the neat polymer but deteriorated a little bit the surface mechanical properties of the initial matrix.

Furthermore, the composite $\mathrm{G}^{\prime \prime}$ decreases to $12 \mathrm{MPa}$ in the case of MIL-53(Cr)/polymer and HKUSTI-1(Cu)/polymer composites compared to $20 \mathrm{MPa}$ for the polymer, indicates a more elastic behavior compared to the initial TMPTA resin. This could be explained by a decrease in the polymer chains mobility and then in the stress transfer in the matrix, by the addition of MOFs crystallites.

In order to select the most suitable irradiation source for photocatalytic degradation tests, optical properties of the MOFs/polymer composites, have also been investigated. 


\subsubsection{Optical properties}

Since the first interest for developing these MOF/polymer composites was their applications for the photocatalytic removal of different pollutants from water, it was important to estimate their band gap energies. Therefore, their optical properties were examined through UV-visible diffuse reflectance spectra and the results are shown in Figure 12 and in Table 7.
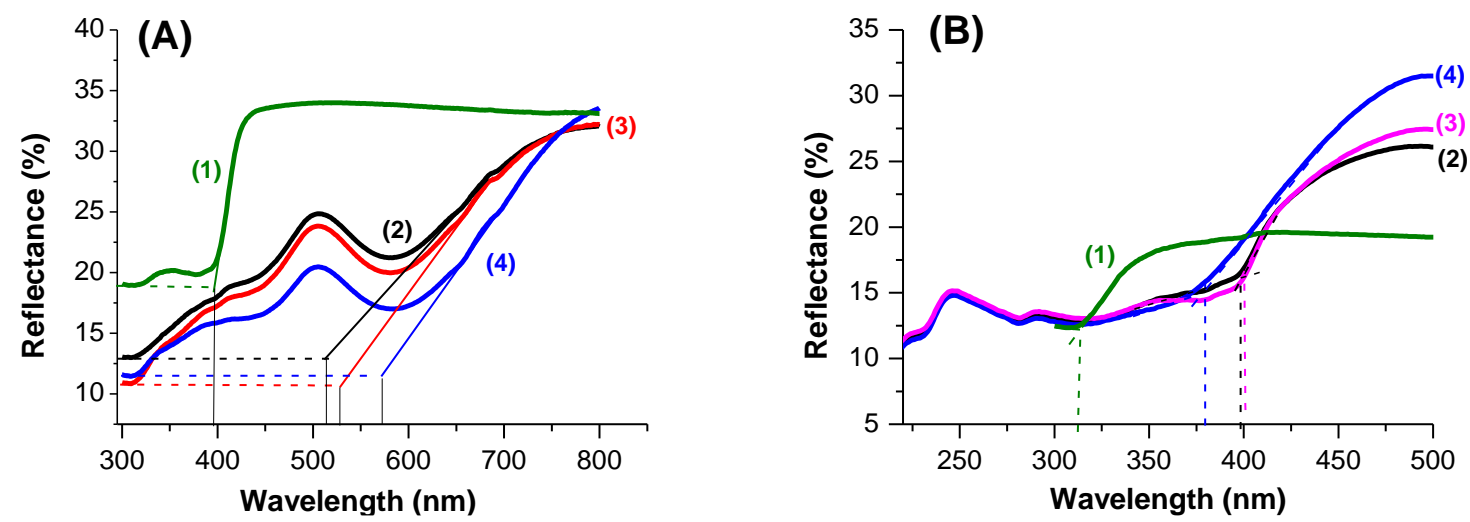

Figure 12 : UV-Visible diffuse reflectance spectra of (A) (1) 1\% $\mathrm{TiO}_{2} /$ polymer composite, (2) $0.5 \%,(3) 1 \%,(4) 2 \%$ MIL-53(Cr)/polymer composites and (B) (1) the polymer, (2) $0.5 \%,(3) 1 \%$ and (4) $2 \%$ HKUSTI-1(Cu)/polymer composites.

Table 7: Bandgap energy values and maximal wavelengths of different synthesized composites with polymer derived from TMPTA.

\begin{tabular}{|c|c|c|}
\hline Composite & Band Gap energy (eV) & $\lambda_{(\max )}(\mathrm{nm})$ \\
\hline Polymer & 3.9 & 318 \\
\hline $1 \% \mathrm{TiO}_{2} /$ polymer & 3.1 & 396 \\
\hline 0.5\% MIL-53(Cr)/polymer & 2.4 & 515 \\
\hline 1\% MIL-53(Cr)/polymer & 2.3 & 520 \\
\hline 2\% MIL-53(Cr)/polymer & 2.1 & 572 \\
\hline $0.5 \%$ HKUSTI-1(Cu)/polymer & 3.1 & 398 \\
\hline 1\% HKUSTI-1(Cu)/polymer & 3.1 & 400 \\
\hline 2\% HKUSTI-1(Cu)/polymer & 3.2 & 379 \\
\hline
\end{tabular}

The gap energies of the different synthesized materials are reported in Table 7. The MIL$53(\mathrm{Cr}) /$ polymer composites showed a band gap energies between 2.1 and $2.4 \mathrm{eV}$, which are 
weaker than that of the $\mathrm{TiO}_{2} /$ polymer composite $(3.1 \mathrm{eV})$. Therefore, depending on source irradiation emitting wavelengths, the developed composites absorbing at longer wavelengths than the $\mathrm{TiO}_{2}$ /polymer composites are expected to be more efficient under visible irradiation, since photocatalytic performance is related to the photocatalysts band structure. Moreover, in the case of MIL-53(Cr)/polymer composites, increasing MOFs mass percentages, causes a slight decrease of their energy bandgaps and therefore probably to an improvement in their photocatalytic performance. Effectiveness of these different synthesized materials for Acid Black photodegradation will be compared later (section 3.4).

\subsection{Photocatalytic activity of the MIL-53(Cr)/polymer composite}

Photocatalytic activities of the synthesized MOF/polymer composites were evaluated during the degradation of Acid Black in aqueous solutions under UV Lamp irradiation. Obtained results are shown in Figure 13.
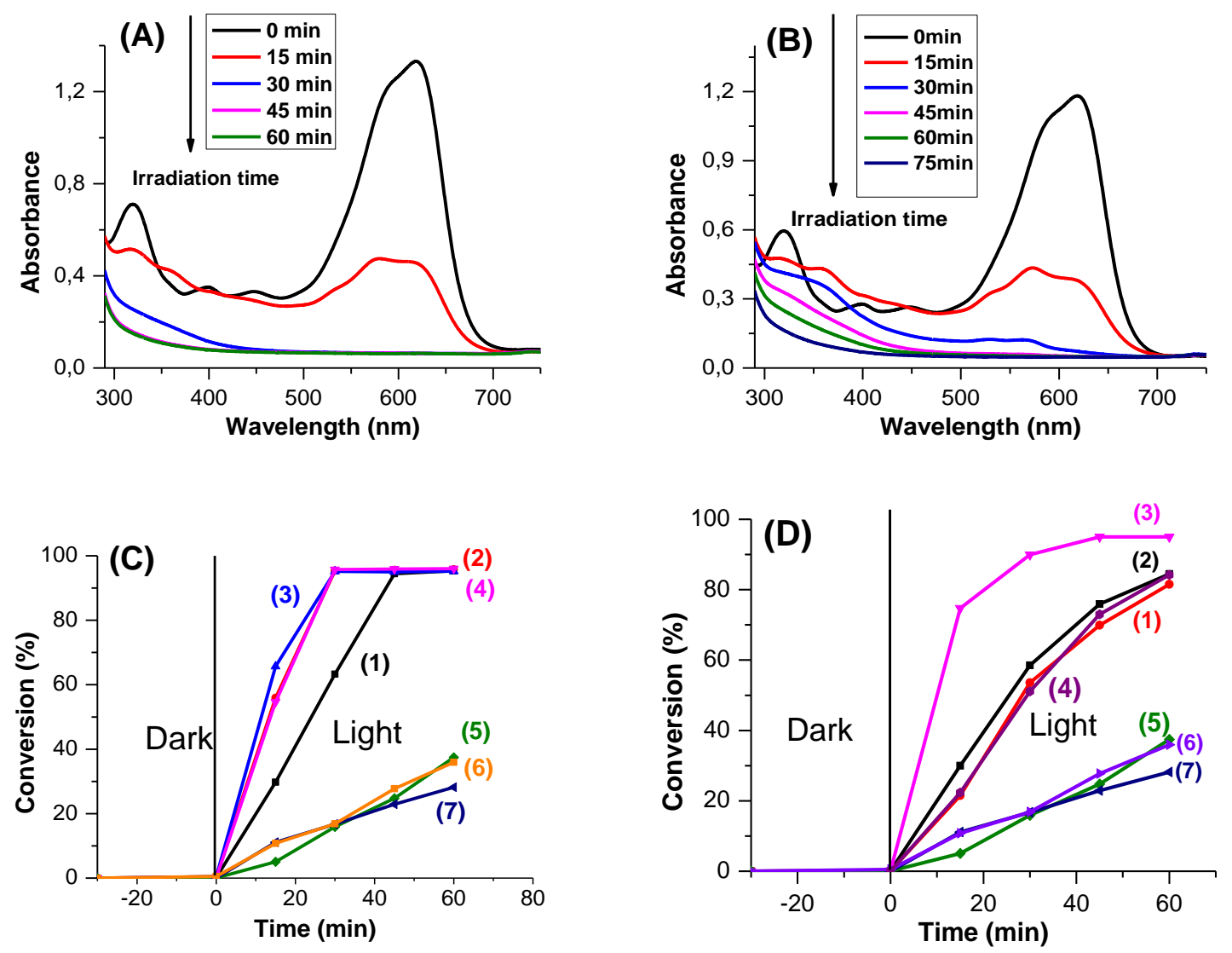

Figure 13: UV-Visible absorption spectra of Acid Black water solutions during the photodegradation process under UV lamp irradiation in the presence of (A) $2 \%$ MIL$53(\mathrm{Cr}) /$ polymer composite and (B) $2 \% \mathrm{HKUSTI}-1(\mathrm{Cu}) /$ polymer composite. $[\mathrm{AB}]_{0}=15 \mathrm{ppm}, \mathrm{pH}$ = 7. Degradation plot of Acid Black (15 ppm) under Omicure lamp irradiation (C) in the 
presence of (1) $0.5 \%$, (2) $1 \%$, (3) $2 \%$ MIL-53(Cr)/polymer composites, (4) $1 \%$ MIL$53(\mathrm{Cr}) /$ polymer composite without iodonium salt, (5) $1 \% \mathrm{TiO}_{2} /$ polymer, (6) polymer, (7) photolysis plot of Acid black without composites and (D) in the presence of (1) $0.5 \%,(2) 1 \%$, (3) $2 \%$ HKUSTI-1(Cu)/polymer composites, (4) 1\% HKUSTI-1(Cu)/polymer without iodoium salt, (5) $1 \% \mathrm{TiO}_{2} /$ polymer composite, (6) polymer and (7) photolysis plot of Acid black without composites.

Acid Black is characterized by two absorption bands: an absorption located between 400 and $700 \mathrm{~nm}$ with an absorption maxima at $618 \mathrm{~nm}$, corresponding to the $\mathrm{n} / \pi *$ transition of the azo $(\mathrm{N}=\mathrm{N})$, which is at the origin of the azo dyes color and used to monitor the dye discoloration. As well as an absorbance between 200 and $400 \mathrm{~nm}$ corresponding to the $n$ / $\pi$ * of benzene and naphthalene transitions (figure $13(\mathrm{~A}, \mathrm{~B})$ ). Decrease of this absorbance during the photocatalytic treatment stipulates the degradation of the dye aromatic part ${ }^{61,62}$.

Figures $13(\mathrm{~A}, \mathrm{~B})$ show that in the presence of both MIL-53 $(\mathrm{Cr}) /$ polymer and HKUSTI$1(\mathrm{Cu}) /$ polymer composites, and by prolongating the irradiation time, the absorption peaks located at $618 \mathrm{~nm}$ and $310 \mathrm{~nm}$ decreased gradually indicating the breaking of the azo $\mathrm{N}=\mathrm{N}$ bond and the naphthalene groups, which results in the formation of aromatic amines: aniline and $p$-nitro aniline ${ }^{63}$ causing the appearance of a peak around $350 \mathrm{~nm}$, which disappears with an increase of the irradiation time.

The formation of intermediates was confirmed by the appearance during photolysis of a light pink color which could correspond to Chromotrope 2B and Chromotrope 2R. This two primary degradation by-products of Acid Black absorbing at 512nm and $514 \mathrm{~nm}$, respectively are reported in the literature ${ }^{64}$. The pink color disappearance was followed by a yellowish color formation corresponding to aniline. At the end of the photocatalytic treatment, the solution color becomes transparent, thus proving the total Acid Black discoloration ${ }^{63}$.

Such spectral and pollutant color changes, were reported previously by A. Troupis and coworkers who have applied various polyoxometalates such as $\mathrm{PW}_{12} \mathrm{O}_{40}{ }^{3-}, \mathrm{SiW}_{12} \mathrm{O}_{40}$ and $\mathrm{P}_{2} \mathrm{~W}_{18} \mathrm{O}_{62}$ for the photocatalytic reductive degradation of Acid Black in the presence of propan2-ol as sacrificial agent ${ }^{63}$. Keiichi TANAKA and coworkers have also outlined the same absorption spectrum transformations when degrading Acid Black by oxidation and reduction processes simultaneously, using a $\mathrm{TiO}_{2}$ suspension ${ }^{65}$. 
Figures 13 (C, D) (curves 7) show the effectiveness of MIL-53 (Cr) /polymer and HKUSTI$1(\mathrm{Cu}) /$ polymer composites for the Acid Black photodegradation. In fact, in the absence of composites and in the presence of the polymer matrix without MOFs, the concentration of this dye was reduced by only $26 \%$ and 35\%, respectively, by irradiating the solution with a UV lamp for $60 \mathrm{~min}$.

However, in the presence of $2 \% \mathrm{MIL}-53(\mathrm{Cr}) /$ polymer and $2 \% \mathrm{HKUSTI}-1(\mathrm{Cu}) /$ polymer composites, the photodegradation of this pollutant becomes faster and reaches respectively $96 \%$ and $90 \%$ (curves 3 ) after only 30 minutes of irradiation. Interstingly, the increase of crystalline MIL-53(Cr) percentages into the polymer from $0.5 \%$ to $1 \%$ and $2 \%$ induces an improvement of the composite photocatalytic performance. Hence, the removal rate was increased from $63 \%$ to $96 \%$ after 30 min of irradiation (See Figure 13 C (curves 1, 2, 3)). Similarly, composites containing $0.5 \%$ to $1 \%$ and $2 \%$ of crystalline HKUSTI-(Cu) degrade $53 \%$, $58 \%$ and $90 \%$, respectively under the same irradiation time (See Figure 13D (curves 1, 2, 3)). Furthermore, only $35 \%$ of Acid Black was removed in the presence of $1 \% \mathrm{TiO}_{2} /$ Polymer. Therefore, the developed MOF/polymer composites are more performant ( $96 \%$ after $60 \mathrm{~min}$ of irradiation), than the Titanium dioxide ( $37 \%$ after 60 min of irradiation).

Monitoring of the Acid Black color change during the photocatalytic process in the presence of the different MOFs/polymer composites is presented in Figure 14. In fact, appearance of the pink and yellow colors indicating the Acid Black reduction and the formation of by-produts, was more pronounced in the presence of HKUSTI-1(Cu)/polymer composite than MIL$53(\mathrm{Cr})$ /polymer composite (figure 14 (b, c, d and f)). This could be explained by the colorant degradation kinetics which was faster in the presence of the second composite than the first one.

(b)

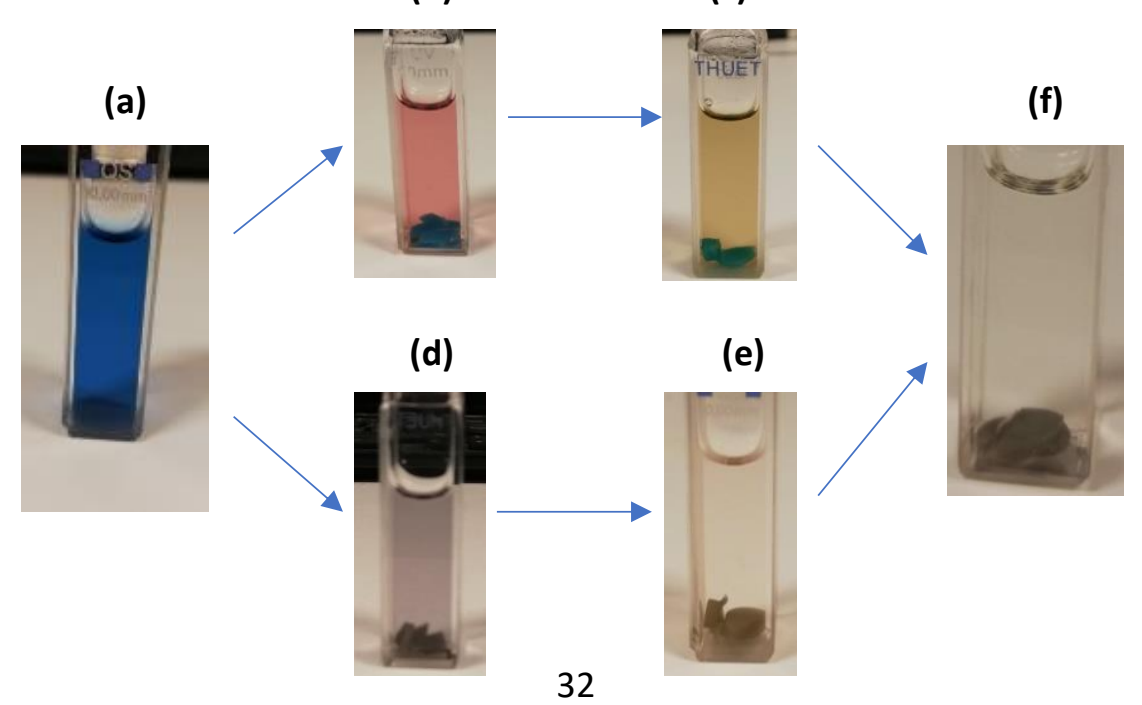


Figure 14 : Monitoring of the Acid Black color change under UV lamp irradiation at (a) $t=0$, $(b, c) t=15$ and $30 \mathrm{~min}$ in the presence of HKUSTI-1(Cu)/polymer composite, $(d, e) t=15$ and $30 \mathrm{~min}$ in the presence of MIL-53(Cr)/polymer composite and (f) $t=60 \mathrm{~min}$ in the presence of the two composites.

\subsection{Proposed photocatalytic degradation mechanism}

Photocatalytic degradation mechanism of Acid Black in the presence of the newly developed photocatalysts upon UV lamp irradiation was investigated by radical scavenging experiments and by photolysis upon different atmospheres (under air and $\mathrm{N}_{2}$ ). Herein, EDTA ${ }^{18,66}$, isopropanol ${ }^{67}, \mathrm{MEHQ}^{68}$ and TEMPO ${ }^{69}$ were applied as scavengers of $\mathrm{h}^{+}$, Hydroxyl radicals $(\cdot \mathrm{OH})$, oxygen active species (RO- and ROO- ) and carbon centred radicals, respectively. In all cases, the scavenger's concentration was fixed to $1 \mathrm{mM}$ and their effects on Acid Black degradation were determined through the variation of the dye concentration reported in Figure 15.
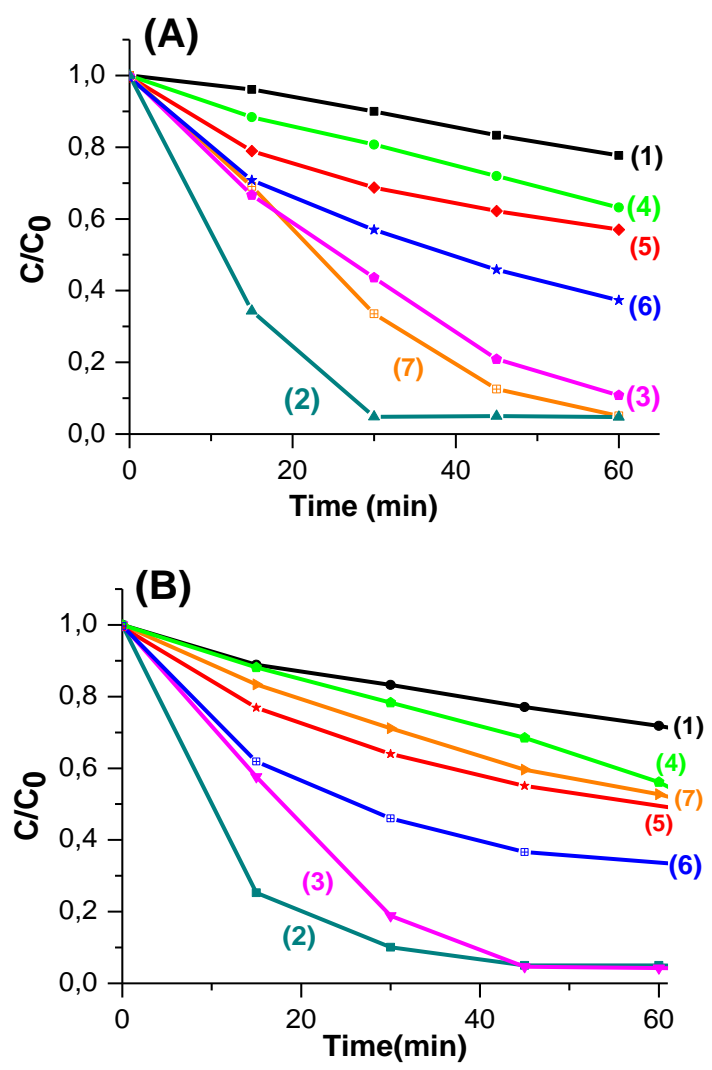

Figure 15: Effects of different scavengers on the degradation of Acid Black under UV lamp irradiation in the presence of (A) $2 \% \mathrm{MIL}-53(\mathrm{Cr}) /$ polymer composite and (B) $2 \%$ HKUSTI- 
1(Cu)/polymer composite : (1) Without composite, without scavangers, (2) Without scavengers, under air, (3) Wihtout scavangers, under $\mathrm{N}_{2}$ and with the addition of (4) EDTA, (5) MEHQ, (6) TEMPOL and (7) Isopropyl alcohol.

Figure 14 ( curves 2 and 3) shows that Acid Black degradation kinetics decreased under $\mathrm{N}_{2}$ atmosphere in the presence of MIL-53(Cr)/polymer and HKUSTI-1(Cu)/polymer composites. This result demonstrates firstly that the dissolved oxygen is involved in the degradation mechanism induced by the two developed composites, and secondly, the ability of the photocatalysts to react directly with the adsorbed dye under anoxic conditions since the Acid black removal could reach $95 \%$ after 45 min of irradiation.

The addition of EDTA and MEHQ decreased the dye degradation from $95 \%$ to 35 and $40 \%$, to $45 \%$ and $44 \%$ after 60 min of UV lamp irradiation in the presence of MIL-53(Cr) and HKUSTI1(Cu) composites, respectively (Figure 15 ( $A$ and B (curves 4, 5 and 2). The obtained results prove that the holes formed in the composites valence bands play a major role in the photocatalytic mechanism by degrading directly the pollutant adsorbed on its surface. The oxygenated active species are also involved in the Acid Black degradation route.

Similarly to EDTA and MEHQ, the TEMPOL presence in the dye solution, have decelerated the kinetics of the photocatalytics process. Indeed, in the presence of this radical scavenger, the pollutant conversion reached only $63 \%$ and $67 \%$ in the presence of repectively MIL53(Cr)/polymer and HKUSTI/polymer composites compared to $96 \%$ attained in the absence of these chemicals (Figure 15 ( $A$ and $B$ ( curves 6 and 2)). Thus, it indicates that the generated carbon radicals play also a crucial role in enhancing the photolysis of the dye.

Also, in the presence of HKUSTI-1(Cu)/polymer composite and under the same conditions, the Acid Black percentage removal was decreased from $95 \%$ to $48 \%$, by adding isopropyl alcohol. However, in the case of MIL-53(Cr)/Polymer composite, the final degradation efficiency has no obvious change by adding this trapper (Figure 15 ( $A$ and $B$ (curves 7 and 2)), proving that hydroxyl radicals formed by the oxidation of ${ }^{-} \mathrm{OH}$ by the generated holes, are more involved in the dye degradation mechanism by the HKUSTI-1(Cu)/polymer composite than the MIL$53(\mathrm{Cr}) /$ polymer composite.

In conclusion, based on the photolysis experiments under air and $\mathrm{N}_{2}$ and in the presence of the different scavengers, we can assume that the Acid Black is degraded by a direct 
mechanism on the holes and electrons formed in the photocomposites surfaces, and by an indirect pathway via the generated oxygenated and carobanted active species.

\subsection{MOF/Polymer composites reusability and stability study}

For practical applications, stability of the photocatalyst is very important. Thus, photocatalytic experiments were repeated (10 times) with the same composite, recovered from the dye solution after a depollution cycle, washed with acetonitrile and water several times, dried and then used again for the next catalytic cycle. Obtained results are shown in Figure 16.
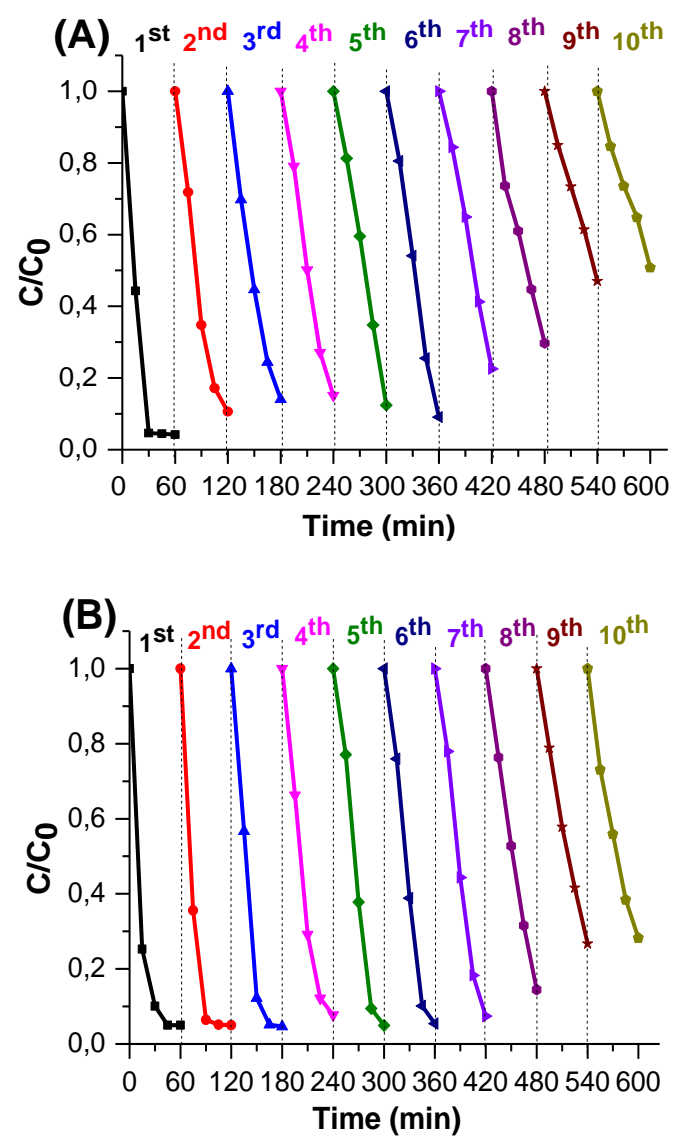

Figure 16 : Ten consecutive Acid Black photodegradation cycles over (A) 2\% MIL$53(\mathrm{Cr}) /$ polymer composite and (B) $2 \%$ HKUSTI- $1(\mathrm{Cu}) /$ polymer composite. $[\mathrm{AB}]_{0}=15 \mathrm{ppm}, \mathrm{pH}=7$, irradiation source: UV Lamp.

The different composites stabilities were evaluated by their reusability for Acid Black photodegradation. Results shown in Figure 16, reveal that the composites MOF/polymer degradation efficiencies started to decline after 8 cycles of dye degradation but is however 
still performant, proving then their high photocatalytic stability by a simple and low cost regeneration process.

Photostability of the different synthesized composites were also evaluated by several characterization techniques including, SEM, EDX and XRD.

XRD patterns shown in Figure 17 confirmed the preservation of HKUSTI-1(Cu) structural integrity after its application for Acid Black degradation. However, in the case of MIL-53(Cr), a new peak appears at around $9.75^{\circ} 2$ Theta which could indicates a changement on the chrominium oxidation degree.

(A)

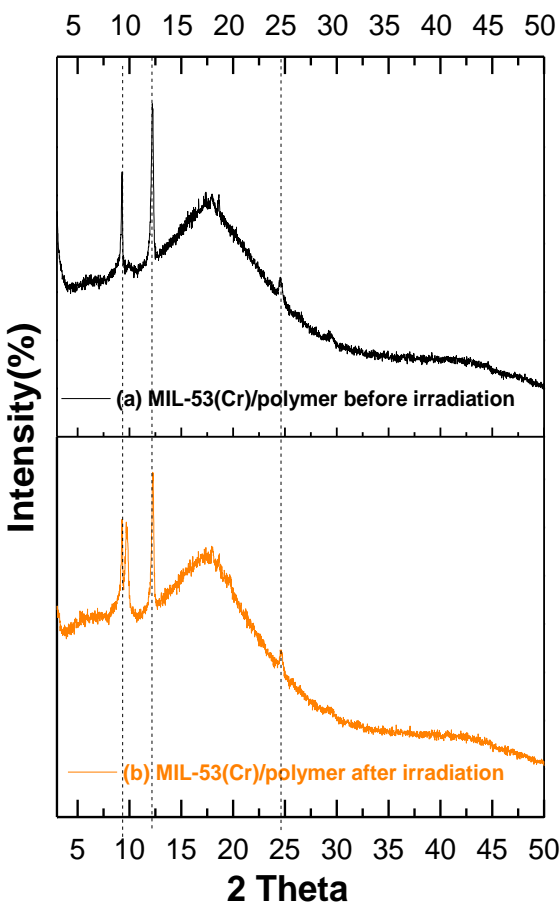

(B) $\begin{array}{llllllllll}5 & 10 & 15 & 20 & 25 & 30 & 35 & 40 & 45 & 50\end{array}$

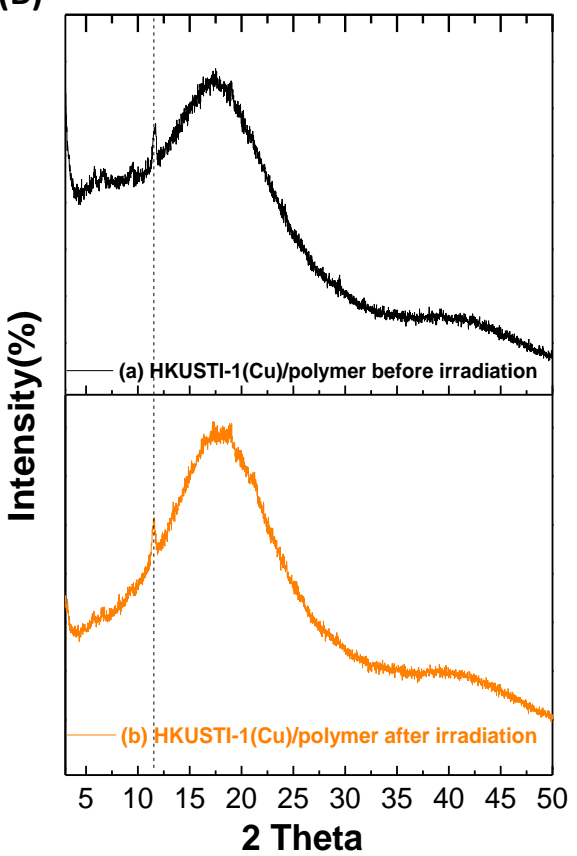

Figure 17: XRD pattern of (A) 2\%MIL-53(Cr)/polymer and (B) 2\% HKUSTI-1(Cu)/polymer composites (a) before and (b) after photodegradation process.

Additionnaly, comparisons of the MOF/polymer composites SEM-EDX images before and after the photocatalytic process (Figures 4 and 5) of photodegradation of Acid Black (Figure 18), showed a slight loss of MOF aggregates at the surface of the polymer film after one photocatalytic treatment cycle, especially for the $2 \%$ HKUSTI-1(Cu)/polymer composite (Figure $18(e, f)$ ) in which the chromium almost totally disappear from this catalyst surface after 10 successive catalytic cycles (Figure $18(i, j)$ ) , explaining then the decrease of Acid Black removal after 8 treatment cycles.

Interstingly, the sectional SEM-EDX images of both MOF/polymer composites present almost 
the same chromium and copper densities before and after degradation cycle which indicates, that MOFs present inside the composite are not affected by the irradiation applied during the degradation and are also involved in to photocatalytic process since, the composites still performant until the tenth cycle.
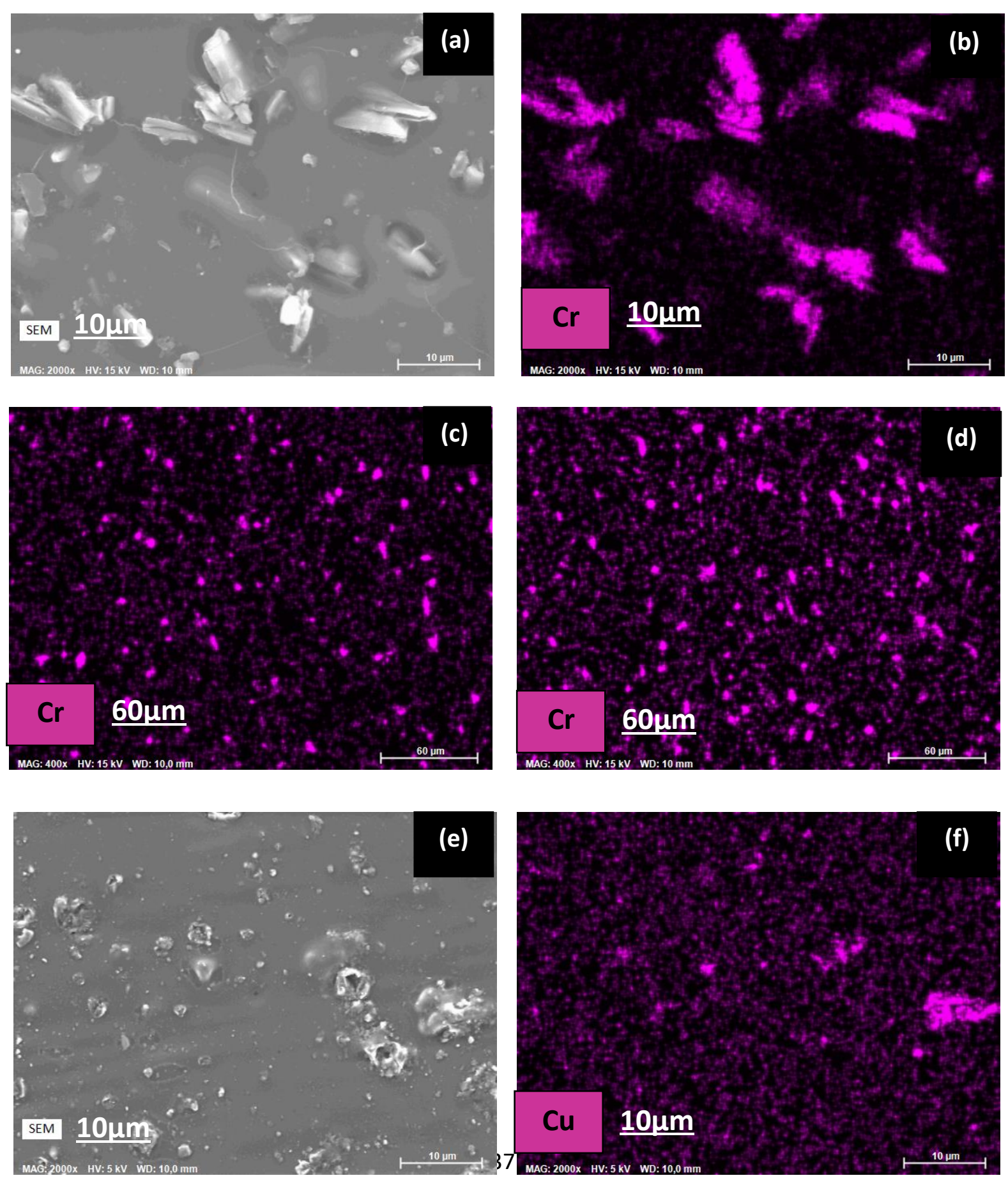

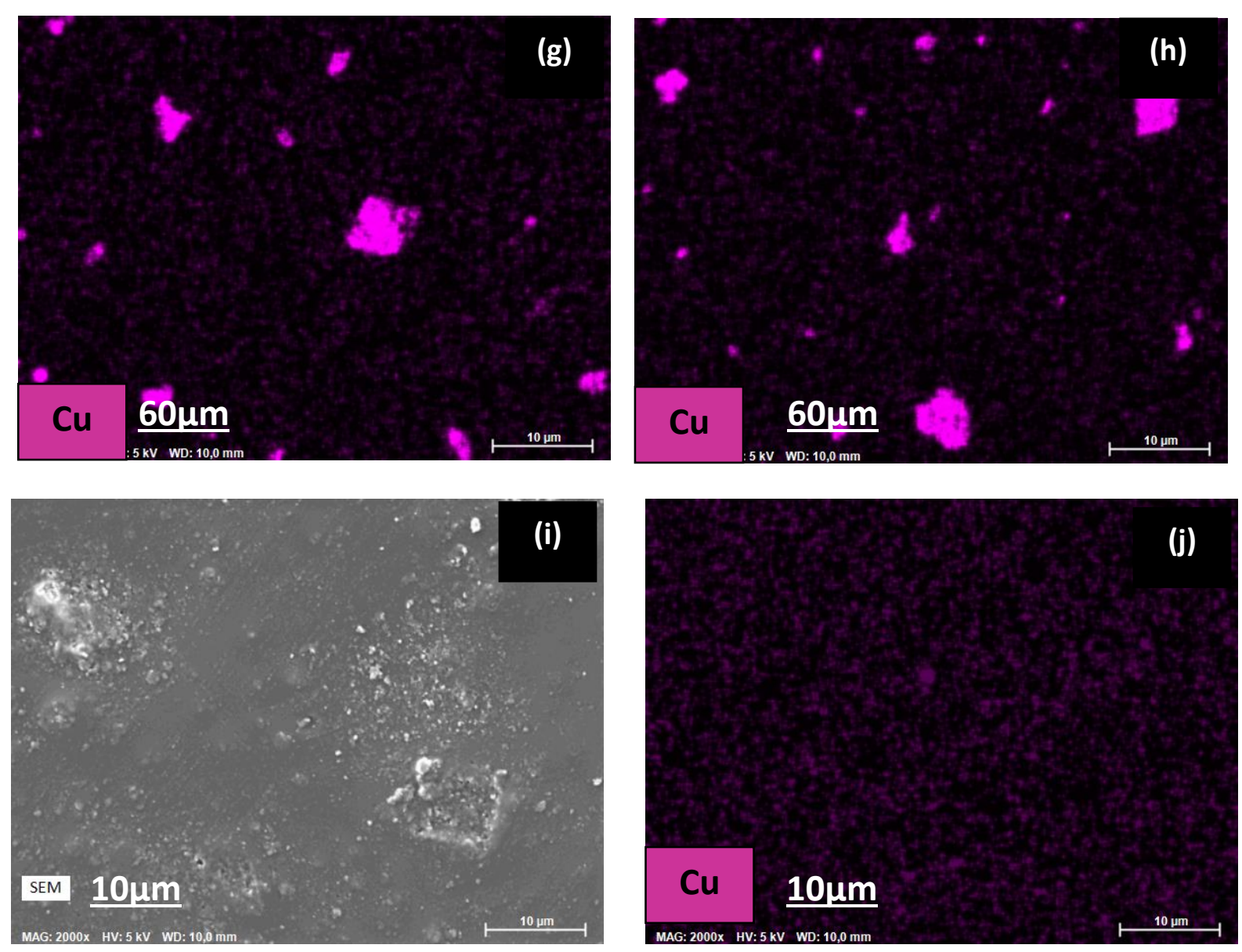

Figure 18: SEM-EDX images of $(a, b) 2 \%$ MIL-53(Cr)/polymer composite after a photodegradation cycle, (e, f) $2 \%$ HKUSTI-1(Cu) after one photodegradation cycle, $(i, j)$ after 10 photodegradation cycles, $(\mathrm{c}, \mathrm{d})$ cutway view of $2 \% \mathrm{MIL}-53(\mathrm{Cr}) /$ polymer composite before and after one photodegradation cyle and $(\mathrm{g}, \mathrm{h})$ cutway view of $2 \% \mathrm{HKUSTI}-1(\mathrm{Cu}) /$ polymer composite before and after one photodegradation cyle.

\section{Conclusion}

In summary, this paper has demonstrated a new, simple and green method to make MOF/Polymer composites with enhanced photocatalytic properties. Synthesis has been achieved by photopolymerization under mild conditions using a visible Light Emitting Diode LED@405 nm as a harmless and low-priced irradiation source. The new proposed composites were characterized by several techniques including SEM, TEM, EDX, XRD and FTIR which have proved the successful MOFs incorporation into the polymer matrix with preserving their initial 
structures. The developed materials exhibit also a relatively low BET surface, a high rigidity as well as a high thermal stability demonstrated by DMA, AFM and ATG analysis, respectively.

The synthesized MOF/Polymer composites were very performant for the Acid Black removal from water, reaching $96 \%$ after $30 \mathrm{~min}$ and $45 \mathrm{~min}$ of UV lamp irradiation, in the presence of $2 \% \mathrm{MIL}-53(\mathrm{Cr}) /$ polymer and $2 \% \mathrm{HKUSTI}-1(\mathrm{Cu}) /$ polymer, respectively. Moreover, these photocatalysts were used 10 times successively with a slightly decrease in their efficiency from the 8th treatment cycle, and were also characterized by XRD and SEM methods after their reuse for Acid Black photodegradation.

In brief, this achievement has improved the mechanical properties and the stability of Metal Organic Frameworks, facilitate their technological application by obtaining materials easy to manipulate and to regenerate. This method will be used to develop several other MOF/Polymer composites in order to enhance their performance in environmentally fields. 
TOC Graphic :
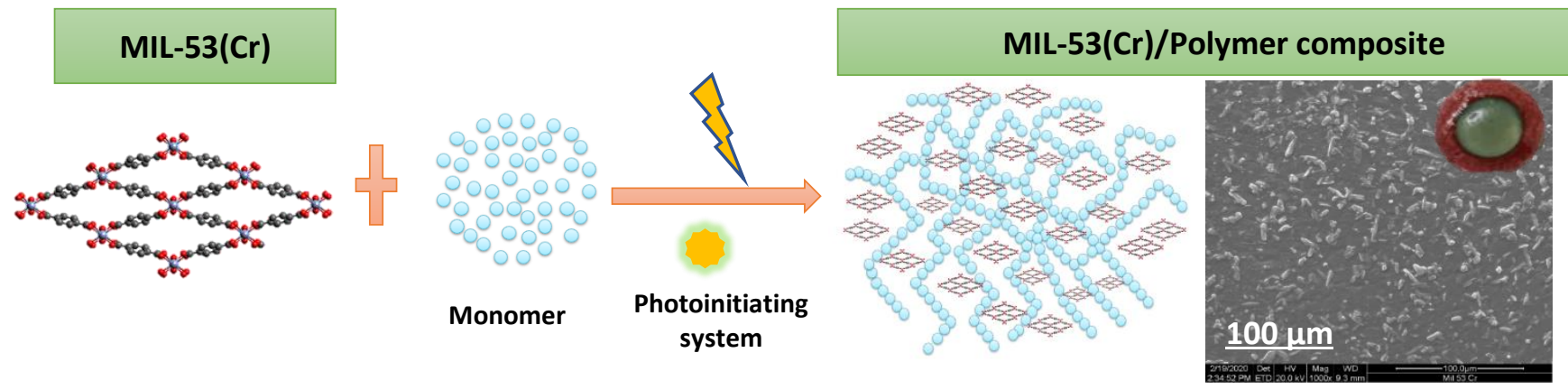

\section{HKUSTI-1(Cu)}

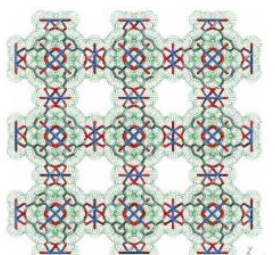

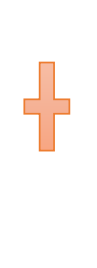

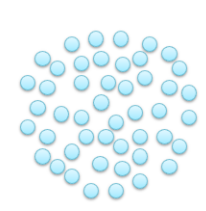

Monomer

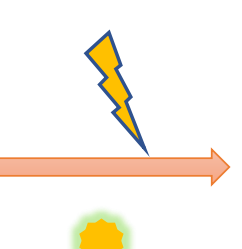

Photoinitiating system

\section{HKUSTI-1(Cu)/Polymer composite}

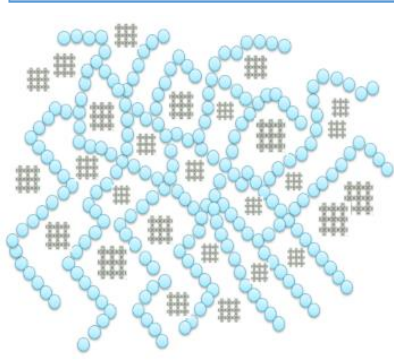

$100 \mathrm{um}$ 
(1) Shivaraju, H. P.; Midhun, G.; Anil Kumar, K. M.; Pallavi, S.; Pallavi, N.; Behzad, S. Degradation of Selected Industrial Dyes Using Mg-Doped TiO2 Polyscales under Natural Sun Light as an Alternative Driving Energy. Appl Water Sci 2017, 7 (7), 3937-3948. https://doi.org/10.1007/s13201-017-0546-0.

(2) Chander, V.; Sharma, B.; Negi, V.; Aswal, R. S.; Singh, P.; Singh, R.; Dobhal, R. Pharmaceutical Compounds in Drinking Water. J Xenobiot 2016, 6 (1). https://doi.org/10.4081/xeno.2016.5774.

(3) Montes-Grajales, D.; Fennix-Agudelo, M.; Miranda-Castro, W. Occurrence of Personal Care Products as Emerging Chemicals of Concern in Water Resources: A Review. Science of The Total Environment 2017, 595, 601-614. https://doi.org/10.1016/j.scitotenv.2017.03.286.

(4) Gupta, N. K.; Ghaffari, Y.; Kim, S.; Bae, J.; Kim, K. S.; Saifuddin, M. Photocatalytic Degradation of Organic Pollutants over MFe $2 \mathrm{O} 4$ (M = Co, Ni, Cu, Zn) Nanoparticles at Neutral PH. Scientific Reports 2020, 10 (1), 4942. https://doi.org/10.1038/s41598-02061930-2.

(5) Shilpa, E. R.; Gayathri, V. Polymer Immobilized Fe(III) Complex of 2Phenylbenzimidazole: An Efficient Catalyst for Photodegradation of Dyes under UV/Visible Light Irradiation. Journal of Saudi Chemical Society 2018, 22 (6), 678-691. https://doi.org/10.1016/j.jscs.2017.12.004.

(6) Djilani, C.; Zaghdoudi, R.; Djazi, F.; Bouchekima, B.; Lallam, A.; Modarressi, A.; Rogalski, M. Adsorption of Dyes on Activated Carbon Prepared from Apricot Stones and Commercial Activated Carbon. Journal of the Taiwan Institute of Chemical Engineers 2015, 53, 112-121. https://doi.org/10.1016/j.jtice.2015.02.025.

(7) Zhu, M.-X.; Lee, L.; Wang, H.-H.; Wang, Z. Removal of an Anionic Dye by Adsorption/Precipitation Processes Using Alkaline White Mud. Journal of Hazardous Materials 2007, 149 (3), 735-741. https://doi.org/10.1016/j.jhazmat.2007.04.037.

(8) Varjani, S.; Rakholiya, P.; Ng, H. Y.; You, S.; Teixeira, J. A. Microbial Degradation of Dyes: An Overview. Bioresource Technology 2020, 314, 123728. https://doi.org/10.1016/j.biortech.2020.123728.

(9) Non-Conventional Textile Waste Water Treatment; El-Nemr, A., Ed.; Nova Science Publishers: New York, 2012. 
(10) Garoma, T.; Matsumoto, S. A.; Wu, Y.; Klinger, R. Removal of Bisphenol A and Its Reaction-Intermediates from Aqueous Solution by Ozonation. Ozone: Science \& Engineering 2010, 32 (5), 338-343. https://doi.org/10.1080/01919512.2010.508484.

(11) Hu, J.; Aizawa, T.; Ookubo, S. Products of Aqueous Chlorination of Bisphenol A and Their Estrogenic Activity. Environ. Sci. Technol. 2002, 36 (9), 1980-1987. https://doi.org/10.1021/es011177b.

(12) Kumar, A.; Sharma, G.; Naushad, Mu.; Al-Muhtaseb, A. H.; Kumar, A.; Hira, I.; Ahamad, T.; Ghfar, A. A.; Stadler, F. J. Visible Photodegradation of Ibuprofen and 2,4-D in Simulated Waste Water Using Sustainable Metal Free-Hybrids Based on Carbon Nitride and Biochar. Journal of Environmental Management 2019, 231, 1164-1175. https://doi.org/10.1016/j.jenvman.2018.11.015.

(13) Rani, A.; Singh, K.; Patel, A. S.; Chakraborti, A.; Kumar, S.; Ghosh, K.; Sharma, P. Visible Light Driven Photocatalysis of Organic Dyes Using SnO2 Decorated MoS2 Nanocomposites. Chemical Physics Letters 2020, 738, 136874. https://doi.org/10.1016/j.cplett.2019.136874.

(14) Zhao, X.; Du, P.; Cai, Z.; Wang, T.; Fu, J.; Liu, W. Photocatalysis of Bisphenol A by an EasySettling Titania/Titanate Composite: Effects of Water Chemistry Factors, Degradation Pathway and Theoretical Calculation. Environmental Pollution 2018, 232, 580-590. https://doi.org/10.1016/j.envpol.2017.09.094.

(15) Ghali, M.; Brahmi, C.; Benltifa, M.; Dumur, F.; Duval, S.; Simonnet-Jégat, C.; MorletSavary, F.; Jellali, S.; Bousselmi, L.; Lalevée, J. New Hybrid Polyoxometalate/Polymer Composites for Photodegradation of Eosin Dye. Journal of Polymer Science Part A: Polymer Chemistry 2019, 57 (14), 1538-1549. https://doi.org/10.1002/pola.29416.

(16) Chen, X.; Wu, Z.; Liu, D.; Gao, Z. Preparation of ZnO Photocatalyst for the Efficient and Rapid Photocatalytic Degradation of Azo Dyes. Nanoscale Research Letters 2017, 12 (1), 143. https://doi.org/10.1186/s11671-017-1904-4.

(17) Luo, J.; Hepel, M. Photoelectrochemical Degradation of Naphthol Blue Black Diazo Dye on WO3 Film Electrode. Electrochimica Acta 2001, 46 (19), 2913-2922. https://doi.org/10.1016/S0013-4686(01)00503-5.

(18) Senasu, T.; Nanan, S. Photocatalytic Performance of CdS Nanomaterials for Photodegradation of Organic Azo Dyes under Artificial Visible Light and Natural Solar Light Irradiation. J Mater Sci: Mater Electron 2017, 28 (23), 17421-17441. https://doi.org/10.1007/s10854-017-7676-x.

(19) Rao, H.; Lu, Z.; Liu, X.; Ge, H.; Zhang, Z.; Zou, P.; He, H.; Wang, Y. Visible Light-Driven Photocatalytic Degradation Performance for Methylene Blue with Different MultiMorphological Features of ZnS. RSC Adv. 2016, 6 (52), 46299-46307. https://doi.org/10.1039/C6RA05212F.

(20) Xiao, J.-D.; Jiang, H.-L. Metal-Organic Frameworks for Photocatalysis and Photothermal Catalysis. Acc. Chem. Res. 2019, 52 (2), 356-366. https://doi.org/10.1021/acs.accounts.8b00521.

(21) Abdpour, S.; Kowsari, E.; Moghaddam, M. R. A. Synthesis of MIL-100(Fe)@MIL-53(Fe) as a Novel Hybrid Photocatalyst and Evaluation Photocatalytic and Photoelectrochemical Performance under Visible Light Irradiation. Journal of Solid State Chemistry 2018, 262, 172-180. https://doi.org/10.1016/j.jssc.2018.03.018.

(22) Tamames-Tabar, C.; García-Márquez, A.; Blanco-Prieto, M. J.; Serre, C.; Horcajada, P. MOFs in Pharmaceutical Technology. In Bio- and Bioinspired Nanomaterials; Ruiz- 
Molina, D., Novio, F., Roscini, C., Eds.; Wiley-VCH Verlag GmbH \& Co. KGaA: Weinheim, Germany, 2014; pp 83-112. https://doi.org/10.1002/9783527675821.ch04.

(23) Li, H.; Wang, K.; Sun, Y.; Lollar, C. T.; Li, J.; Zhou, H.-C. Recent Advances in Gas Storage and Separation Using Metal-Organic Frameworks. Materials Today 2018, 21 (2), 108121. https://doi.org/10.1016/j.mattod.2017.07.006.

(24) Carboni, M.; Abney, C. W.; Liu, S.; Lin, W. Highly Porous and Stable Metal-Organic Frameworks for Uranium Extraction. Chem. Sci. 2013, 4 (6), 2396. https://doi.org/10.1039/c3sc50230a.

(25) Dhakshinamoorthy, A.; Li, Z.; Garcia, H. Catalysis and Photocatalysis by Metal Organic Frameworks. Chem. Soc. Rev. 2018, 47 (22), 8134-8172. https://doi.org/10.1039/C8CS00256H.

(26) Wang, Q.; Gao, Q.; Al-Enizi, A. M.; Nafady, A.; Ma, S. Recent Advances in MOF-Based Photocatalysis: Environmental Remediation under Visible Light. Inorg. Chem. Front. 2020, 7 (2), 300-339. https://doi.org/10.1039/C9QI01120J.

(27) Alvaro, M.; Carbonell, E.; Ferrer, B.; Llabrés i Xamena, F. X.; Garcia, H. Semiconductor Behavior of a Metal-Organic Framework (MOF). Chem. Eur. J. 2007, 13 (18), 5106-5112. https://doi.org/10.1002/chem.200601003.

(28) Bůžek, D.; Demel, J.; Lang, K. Zirconium Metal-Organic Framework UiO-66: Stability in an Aqueous Environment and Its Relevance for Organophosphate Degradation. Inorg. Chem. 2018, 57 (22), 14290-14297. https://doi.org/10.1021/acs.inorgchem.8b02360.

(29) George, P.; Dhabarde, N. R.; Chowdhury, P. Rapid Synthesis of Titanium Based Metal Organic Framework (MIL-125) via Microwave Route and Its Performance Evaluation in Photocatalysis. Materials Letters 2017, 186, 151-154. https://doi.org/10.1016/j.matlet.2016.09.099.

(30) Wang, D.; Li, Z. Iron-Based Metal-Organic Frameworks (MOFs) for Visible-Light-Induced Photocatalysis. Res Chem Intermed 2017, 43 (9), 5169-5186. https://doi.org/10.1007/s11164-017-3042-0.

(31) Du, J.-J.; Yuan, Y.-P.; Sun, J.-X.; Peng, F.-M.; Jiang, X.; Qiu, L.-G.; Xie, A.-J.; Shen, Y.-H.; Zhu, J.-F. New Photocatalysts Based on MIL-53 Metal-Organic Frameworks for the Decolorization of Methylene Blue Dye. Journal of Hazardous Materials 2011, 190 (1-3), 945-951. https://doi.org/10.1016/j.jhazmat.2011.04.029.

(32) Peng, L.; Yang, S.; Sun, D. T.; Asgari, M.; Queen, W. L. MOF/Polymer Composite Synthesized Using a Double Solvent Method Offers Enhanced Water and $\mathrm{CO}_{2}$ Adsorption Properties. Chem. Commun. 2018, 54 (75), 10602-10605. https://doi.org/10.1039/C8CC05428B.

(33) Pastore, V. J.; Cook, T. R.; Rzayev, J. Polymer-MOF Hybrid Composites with High Porosity and Stability through Surface-Selective Ligand Exchange. Chem. Mater. 2018, 30 (23), 8639-8649. https://doi.org/10.1021/acs.chemmater.8b03881.

(34) Fei, H.; Pullen, S.; Wagner, A.; Ott, S.; Cohen, S. M. Functionalization of Robust Zr( IV )Based Metal-Organic Framework Films via a Postsynthetic Ligand Exchange. Chem. Commun. 2015, 51 (1), 66-69. https://doi.org/10.1039/C4CC08218D.

(35) Fei, H.; Cahill, J. F.; Prather, K. A.; Cohen, S. M. Tandem Postsynthetic Metal Ion and Ligand Exchange in Zeolitic Imidazolate Frameworks. Inorg. Chem. 2013, 52 (7), 40114016. https://doi.org/10.1021/ic400048g.

(36) Ehrhart, I. C.; Parker, P. E.; Weidner, W. J.; Dabney, J. M.; Scott, J. B.; Haddy, F. J. Coronary Vascular and Myocardial Responses to Carotid Body Stimulation in the Dog. 
$\begin{array}{llllll}\text { Am. Jm } & \text { Physiol. } & \text { 1975, } & 29 & \text { (3), } & \text { 754-760. }\end{array}$ https://doi.org/10.1152/ajplegacy.1975.229.3.754.

(37) Zhuang, J.; Young, A. P.; Tsung, C.-K. Integration of Biomolecules with Metal-Organic Frameworks. Small 2017, 13 (32), 1700880. https://doi.org/10.1002/smll.201700880.

(38) O'Neill, L. D.; Zhang, H.; Bradshaw, D. Macro-/Microporous MOF Composite Beads. J. Mater. Chem. 2010, 20 (27), 5720. https://doi.org/10.1039/c0jm00515k.

(39) Tehfe, M.; Louradour, F.; Lalevée, J.; Fouassier, J.-P. Photopolymerization Reactions: On the Way to a Green and Sustainable Chemistry. Applied Sciences 2013, 3 (2), 490-514. https://doi.org/10.3390/app3020490.

(40) Kalaj, M.; Denny, M. S.; Bentz, K. C.; Palomba, J. M.; Cohen, S. M. Nylon-MOF Composites through Postsynthetic Polymerization. Angew. Chem. Int. Ed. 2019, 58 (8), 2336-2340. https://doi.org/10.1002/anie.201812655.

(41) Saroyan, H.; Kyzas, G.; Deliyanni, E. Effective Dye Degradation by Graphene Oxide $\begin{array}{llll}\text { Supported } \quad \text { Manganese } & \text { Oxide. Processes 2019, }\end{array}$ https://doi.org/10.3390/pr7010040.

(42) Rauf, M. A.; Meetani, M. A.; Hisaindee, S. An Overview on the Photocatalytic Degradation of Azo Dyes in the Presence of TiO2 Doped with Selective Transition $\begin{array}{lllll}\text { Metals. } & \text { 2011, Desalination } & 276 & \text { 13-27. }\end{array}$ https://doi.org/10.1016/j.desal.2011.03.071.

(43) Millange, F.; Serre, C.; Férey, G. Synthesis, Structure Determination and Properties of MIL-53as and MIL-53ht: The First Criii Hybrid Inorganic-Organic Microporous Solids: $\mathrm{Criii}(\mathrm{OH}) \cdot\{\mathrm{O} 2 \mathrm{C}-\mathrm{C} 6 \mathrm{H} 4-\mathrm{CO} 2\} \cdot\{\mathrm{HO} 2 \mathrm{C}-\mathrm{C} 6 \mathrm{H} 4-\mathrm{CO} 2 \mathrm{H}\} \times$ Electronic Supplementary Information (ESI) Available: Crystal Data, Atomic Coordinates and Metrical Parameters for MIL-53as and MIL-53ht. See Http://Www.Rsc.Org/Suppdata/Cc/B2/B201381a/. Chem. Commun. 2002, No. 8, 822-823. https://doi.org/10.1039/b201381a.

(44) Serre, C.; Millange, F.; Thouvenot, C.; Noguès, M.; Marsolier, G.; Louër, D.; Férey, G. Very Large Breathing Effect in the First Nanoporous Chromium(III)-Based Solids: MIL-53 or $\mathrm{Cr}{ }^{\text {III }}(\mathrm{OH}) \cdot\left\{\mathrm{O}_{2} \mathrm{C}_{-} \mathrm{C}_{6} \mathrm{H}_{4}-\mathrm{CO}_{2}\right\} \cdot\left\{\mathrm{HO}_{2} \mathrm{C}-\mathrm{C}_{6} \mathrm{H}_{4}-\mathrm{CO}_{2} \mathrm{H}\right\}_{x} \cdot \mathrm{H}_{2} \mathrm{O}$ y. J. Am. Chem. Soc. 2002, 124 (45), 13519-13526. https://doi.org/10.1021/ja0276974.

(45) Guillou, N.; Millange, F.; Walton, R. I. Rapid and Reversible Formation of a Crystalline Hydrate of a Metal-Organic Framework Containing a Tube of Hydrogen-Bonded Water. Chem. Commun. 2011, 47 (2), 713-715. https://doi.org/10.1039/C0CC03882B.

(46) Chui, S. S. A Chemically Functionalizable Nanoporous Material [Cu3(TMA)2(H2O)3]n. Science 1999, 283 (5405), 1148-1150. https://doi.org/10.1126/science.283.5405.1148.

(47) Rowsell, J. L. C.; Yaghi, O. M. Effects of Functionalization, Catenation, and Variation of the Metal Oxide and Organic Linking Units on the Low-Pressure Hydrogen Adsorption Properties of Metal-Organic Frameworks. J. Am. Chem. Soc. 2006, 128 (4), 1304-1315. https://doi.org/10.1021/ja056639q.

(48) Millange, F.; Medina, M. I.; Guillou, N.; Férey, G.; Golden, K. M.; Walton, R. I. TimeResolved In Situ Diffraction Study of the Solvothermal Crystallization of Some Prototypical Metal-Organic Frameworks. Angewandte Chemie International Edition 2010, 49 (4), 763-766. https://doi.org/10.1002/anie.200905627.

(49) Omidian, H.; Hasherni, S.; Askari, F.; Nafisi, S. Swelling and Crosslink Density Measurements for Hydrogels; 1993.

(50) Kalaj, M.; Bentz, K. C.; Ayala, S.; Palomba, J. M.; Barcus, K. S.; Katayama, Y.; Cohen, S. M. MOF-Polymer Hybrid Materials: From Simple Composites to Tailored Architectures. Chem. Rev. 2020, 120 (16), 8267-8302. https://doi.org/10.1021/acs.chemrev.9b00575. 
(51) Sofi, F. A.; Majid, K.; Mehraj, O. The Visible Light Driven Copper Based Metal-OrganicFramework Heterojunction:HKUST-1@Ag-Ag3PO4 for Plasmon Enhanced Visible Light Photocatalysis. Journal of Alloys and Compounds 2018, 737, 798-808. https://doi.org/10.1016/j.jallcom.2017.12.141.

(52) Sun, X.; Gu, X.; Xu, W.; Chen, W.-J.; Xia, Q.; Pan, X.; Zhao, X.; Li, Y.; Wu, Q.-H. Novel Hierarchical Fe(III)-Doped Cu-MOFs With Enhanced Adsorption of Benzene Vapor. Front. Chem. 2019, 7, 652. https://doi.org/10.3389/fchem.2019.00652.

(53) Azhar, M. R.; Abid, H. R.; Sun, H.; Periasamy, V.; Tadé, M. O.; Wang, S. Excellent Performance of Copper Based Metal Organic Framework in Adsorptive Removal of Toxic Sulfonamide Antibiotics from Wastewater. Journal of Colloid and Interface Science 2016, 478, 344-352. https://doi.org/10.1016/j.jcis.2016.06.032.

(54) Schlichte, K.; Kratzke, T.; Kaskel, S. Improved Synthesis, Thermal Stability and Catalytic Properties of the Metal-Organic Framework Compound Cu3(BTC)2. Microporous and $\begin{array}{lllll}\text { Mesoporous } \quad \text { Materials } & \text { 2004, } & \text { 81-88. }\end{array}$ https://doi.org/10.1016/j.micromeso.2003.12.027.

(55) Calvez, C. L.; Zouboulaki, M.; Petit, C.; Peeva, L.; Shirshova, N. One Step Synthesis of MOF-Polymer Composites. RSC Adv. 2016, 6 (21), 17314-17317. https://doi.org/10.1039/C5RA25238E.

(56) Düren, T.; Millange, F.; Férey, G.; Walton, K. S.; Snurr, R. Q. Calculating Geometric Surface Areas as a Characterization Tool for Metal-Organic Frameworks. J. Phys. Chem. C 2007, 111 (42), 15350-15356. https://doi.org/10.1021/jp074723h.

(57) Ghali, M.; Brahmi, C.; Benltifa, M.; Vaulot, C.; Airoudj, A.; Fioux, P.; Dumur, F.; SimonnetJégat, C.; Morlet-Savary, F.; Jellali, S.; Bousselmi, L.; Lalevée, J. Characterization of Polyoxometalate/Polymer Photo-composites: A Toolbox for the Photodegradation of Organic Pollutants. Journal of Polymer Science 2020, pol.20200568. https://doi.org/10.1002/pol.20200568.

(58) Giliopoulos, D.; Zamboulis, A.; Giannakoudakis, D.; Bikiaris, D.; Triantafyllidis, K. Polymer/Metal Organic Framework (MOF) Nanocomposites for Biomedical $\begin{array}{lllll}\text { Applications. } & \text { Molecules } & 25 & \end{array}$ https://doi.org/10.3390/molecules25010185.

(59) Wickenheisser, M.; Paul, T.; Janiak, C. Prospects of Monolithic MILMOF@poly(NIPAM)HIPE Composites as Water Sorption Materials. Microporous and Mesoporous Materials 2016, 220, 258-269. https://doi.org/10.1016/j.micromeso.2015.09.008.

(60) Schwab, M. G.; Senkovska, I.; Rose, M.; Koch, M.; Pahnke, J.; Jonschker, G.; Kaskel, S. MOF@PolyHIPEs. Adv. Eng. Mater. 2008, 10 (12), 1151-1155. https://doi.org/10.1002/adem.200800189.

(61) Bechiri, O.; Abbessi, M. Catalytic Oxidation of Naphtol Blue Black in Water: Effect of Operating Parameters and the Type of Catalyst. Journal of Water and Environmental Nanotechnology 2017, 2 (1), 9-16. https://doi.org/10.7508/jwent.2017.01.002.

(62) Onder, S.; Celebi, M.; Altikatoglu, M.; Hatipoglu, A.; Kuzu, H. Decolorization of Naphthol Blue Black Using the Horseradish Peroxidase. Appl Biochem Biotechnol 2011, 163 (3), 433-443. https://doi.org/10.1007/s12010-010-9051-8.

(63) Troupis, A.; Gkika, E.; Hiskia, A.; Papaconstantinou, E. Photocatalytic Reductive Destruction of Azo Dyes by Polyoxometalates. Journal of Advanced Oxidation Technologies 2007, 10 (1). https://doi.org/10.1515/jaots-2007-0113. 
(64) Nasr, C.; Vinodgopal, K.; Fisher, L.; Hotchandani, S.; Chattopadhyay, A. K.; Kamat, P. V. Environmental Photochemistry on Semiconductor Surfaces. Visible Light Induced Degradation of a Textile Diazo Dye, Naphthol Blue Black, on TiO ${ }_{2}$ Nanoparticles. J. Phys. Chem. 1996, 100 (20), 8436-8442. https://doi.org/10.1021/jp953556v.

(65) Tanaka, K.; Padermpole, K.; Hisanaga, T. Photocatalytic Degradation of Commercial Azo Dyes. Water Research 2000, 34 (1), 327-333. https://doi.org/10.1016/S00431354(99)00093-7.

(66) Pedrosa, M.; Da Silva, E. S.; Pastrana-Martínez, L. M.; Drazic, G.; Falaras, P.; Faria, J. L.; Figueiredo, J. L.; Silva, A. M. T. Hummers' and Brodie's Graphene Oxides as Photocatalysts for Phenol Degradation. Journal of Colloid and Interface Science 2020, 567, 243-255. https://doi.org/10.1016/j.jcis.2020.01.093.

(67) Tang, L.; Jia, C.; Xue, Y.; Li, L.; Wang, A.; Xu, G.; Liu, N.; Wu, M. Fabrication of Compressible and Recyclable Macroscopic G-C3N4/GO Aerogel Hybrids for Visible-Light Harvesting: A Promising Strategy for Water Remediation. Applied Catalysis B: Environmental 2017, 219, 241-248. https://doi.org/10.1016/j.apcatb.2017.07.053.

(68) Cutié, S. S.; Henton, D. E.; Powell, C.; Reim, R. E.; Smith, P. B.; Staples, T. L. The Effects of MEHQ on the Polymerization of Acrylic Acid in the Preparation of Superabsorbent Gels. Journal of Applied Polymer Science 1997, 64 (3), 577-589. https://doi.org/10.1002/(SICI)1097-4628(19970418)64:3<577::AID-APP14>3.0.CO;2-V.

(69) Liang, J.; Liu, F.; Li, M.; Liu, W.; Tong, M. Facile Synthesis of Magnetic Fe304@BiOl@AgI for Water Decontamination with Visible Light Irradiation: Different Mechanisms for Different Organic Pollutants Degradation and Bacterial Disinfection. Water Research 2018, 137, 120-129. https://doi.org/10.1016/j.watres.2018.03.027. 